\title{
Helium, Argon, and Carbon in Some Natural Gases
}

\author{
R. E. Zartman and G. J. Wasserburg \\ The California Institute of Technology \\ AND \\ J. H. REYNOLDS \\ University of Califormia \\ Berkeley, California
}

\begin{abstract}
Thirty-nine samples of natural gases representing varied chemical compositions and geological occurrences were analyzed for their helium, radiogenic argon, and atmospheric argon contents. The total range in the (He/A $)_{\text {rad }}$ ratio was found to be 1.6 to 130 with most samples having values between 6 and 25 . This range of values is essentially equal to the production ratio from the uranium, thorium, and potassium in average igneous rocks and a wide variety of sediments. This indicates that all of these natural gases have obtained their radiogenic gases from rather average rock types. This is true in spite of the fact that the gases range in helium content from 37 to $62,000 \mathrm{ppm}$.

A theoretical discussion of the origin of helium and argon in natural gases is given. It can be shown from the ratio of nitrogen to atmospheric argon that most of the nitrogen in these gases cannot come from the entrapment of air. From a consideration of the concentration of atmospheric argon in natural gases it is possible to estimate the proportion of gaseous and aqueous phases assuming diffusive equilibrium.

The isotopic composition of the carbon in the methane of these gases was found to be very light. It was shown that for coexisting $\mathrm{CH}_{4}-\mathrm{CO}_{2}$ pairs the carbon dioxide was always isotopically heavier.
\end{abstract}

\section{INTRODUCTION}

The purpose of this study was to investigate the relationship between the abundances of helium and argon in natural gases of different compositions and environments and to examine the isotopic composition of the carbon in these gases. Since the discovery of terrestrial helium in natural gases by Cady and McFarland [1906], a vigorous search has been made for helium-rich gases, and a considerable number of total gas analyses that include helium determinations exist in the literature. These have been made using both volumetric and mass spectrometric techniques [Rogers, 1921; Anderson and Hinson, 1951; Boone, 1958].

The origin of high helium natural gases, some of which have helium contents as great as 10 per cent, has been the subject of considerable speculation. The $\mathrm{He}^{4}$ contained in them is presumably the product of the radioactive decay of $\mathrm{U}^{235}, \mathrm{U}^{238}$, and $\mathrm{Th}^{232}$, and their intermediate daughter products. A fundamental question arises whether these quantities of helium represent the accumulated decay products of a reservoir greatly enriched in $U$ and/or $T h$, or the accumulation from a rather normal rock reservoir. Lastly, there exists the possibility that the helium represents some more primordial gases trapped in the earth during its early history and subsequently partly released into stratigraphic and structural traps. These various possibilities have been recognized by some of the earliest investigators in the field [Rogers, 1921]. It has been found [Faul, Gott, Manger, Mytton, and Sakakura, 1954; Sakakura, Lindberg, and Faul, 1959] that several helium wells, i.e., wells containing over 0.5 per cent helium, are radioactive owing to a high radon content and appear to be associated with some uraniferous petroleum residues. Other high helium wells, however, are devoid of such radioactivity. In addition, many well gases have a high radon content and only small concentrations of helium [Satterly and McLennan, 1918]. The composition of helium-rich gases has been found to be quite variable, although in some gas fields a correlation has been suggested between helium and nitrogen content. 
The isotopic composition of helium from gas wells has been investigated by Aldrich and Nier [1948] who report values of $\mathrm{He}^{\mathrm{j}} / \mathrm{He}^{4} \simeq \mathbf{1 0}^{-7}$. The results of these authors represent the only published data on $\mathrm{He}^{\mathrm{s}}$ content in terrestrial gases. The origin of the $\mathrm{He}^{\mathrm{d}}$ in these gases has been considered by several workers. Hill [1941] suggested that this isotope of helium could be produced in rocks by the reaction $\operatorname{Li}^{\circ}(n, \alpha) \mathrm{H}^{\circ} \rightarrow$ $\mathrm{He}^{\mathrm{s}}+\beta^{-}$. More recently, Morrison and Pine [1955] have discussed the relative production of $\mathrm{He}^{\mathrm{s}}$ and $\mathrm{He}^{4}$ in rocks. As shown by Wetherill $[1953,1954]$, the principal sources of neutrons are the reaction $\mathrm{O}^{18}(\alpha, n) \mathrm{Ne}^{21}$ and spontaneous fission of $U^{238}$. By considering the various nuclear reactions which compete for neutrons, Morrison and Pine conclude that the $\mathrm{He}^{\mathrm{s}} / \mathrm{He}^{4}$ ratio observed by Aldrich and Nier in natural gases is most reasonably the product of these processes in materials which contain neither uranium nor thorium, or both, in very great concentration. Their arguments would not, however, preclude the origin of this helium to be from finely divided uranium minerals disseminated in a rather normal rock. This would permit uranium concentrations of up to a few tenths of 1 per cent.

The radioactive decay of $K^{40}$ gives rise to the possibility of high argon-containing natural gases. Since potassium is a principal element in most crustal rocks as compared with uranium and thorium, a study of the ratio of radiogenic helium to radiogenic argon, $\left(\mathrm{He}^{4} / \mathrm{A}^{40}\right)_{\mathrm{rad}}$ gives more direct information on the possible source of helium gas wells.

Some results using this approach were reported by Wasserburg, Czamanske, Faul, and Hayden [1957] for some helium wells in the Texas Panhandle. These workers showed that the argon in four helium wells was about 70 per cent radiogenic and that the ratio $\left(\mathrm{He}^{4} / \mathrm{A}^{10}\right)_{\mathrm{rad}}$ was about 10 . This ratio was well within the values to be expected from the present-day production rates of $\mathrm{He}^{4}$ and $\mathrm{A}^{40}$ in normal igneous rocks. They therefore concluded that these helium wells were probably formed from the accumulated radiogenic gases found in rocks with a ratio of $\mathrm{U} / \mathrm{K}$ typical of normal igneous rocks, and that in no way could these gases be the result of accumulation from an enriched uranium reservoir. For these samples it was shown that the $\mathrm{A}^{\mathrm{s}} / \mathrm{A}^{\mathrm{se}}$ ratio was the same as that found in atmospheric argon and it was therefore possible to make estimates of the contribution of atmospheric gases.

\section{Experimental Techniques}

We have studied a variety of natural gases covering a wide compositional and environmental range in order to attempt some understanding of their origin. In this study we have restricted our efforts to well gases and have not investigated volcanic or hot spring emanations. Thirty-nine samples were analyzed for their helium and argon contents and for isotopic composition. Partial gas analyses for other major constituents were also made. The isotopic composition of the total gas carbon, methane carbon, and carbon dioxide carbon were determined. The results of this investigation are presented in Tables 1 and 2, together with pertinent well data for each sample. The accompanying total gas analyses represent data supplied us by the participating petroleum and natural gas companies, partial gas analyses performed in our laboratory, and a combination of these two sources. With the exception of three samples, the $\mathrm{H}_{2} \mathrm{~S}$ contents were less than 0.01 per cent. For samples 14 , 34 , and 35 , the $\mathrm{H}_{2} \mathrm{~S}$ contents were $0.04,0.09$, and 0.12 per cent, respectively.

With the exception of samples $29,30,31$, and 32 , the well gases were collected using standard high-pressure, stainless steel gas cylinders with valves on both ends. The cylinders were connected to the gas source and purged of air by passing well gas through them under positive pressure for several minutes. The outlet valve was then closed, and the pressure in the cylinder was allowed to reach a satisfactory value (203000 psig), and then the valve to the source was closed. All of these sample vessels were at a pressure of considerably over 1 atmosphere when they were used for analysis. Samples 29-32 from the Texas Panhandle gas field were obtained by Henry Faul in 1954. They were collected in glass cylinders that had openings at both ends. After allowing the gas to pass through the cylinders at slight positive pressure for a few minutes, both ends of the vessel were sealed off. In every instance the helium, argon, and carbon analyses were done on the same sample.

The gas cylinders were joined onto a vacuum line (Fig, 1) with metal-to-glass couplings and the system was evacuated with all the furnaces heated and outgassed before each run. After the 


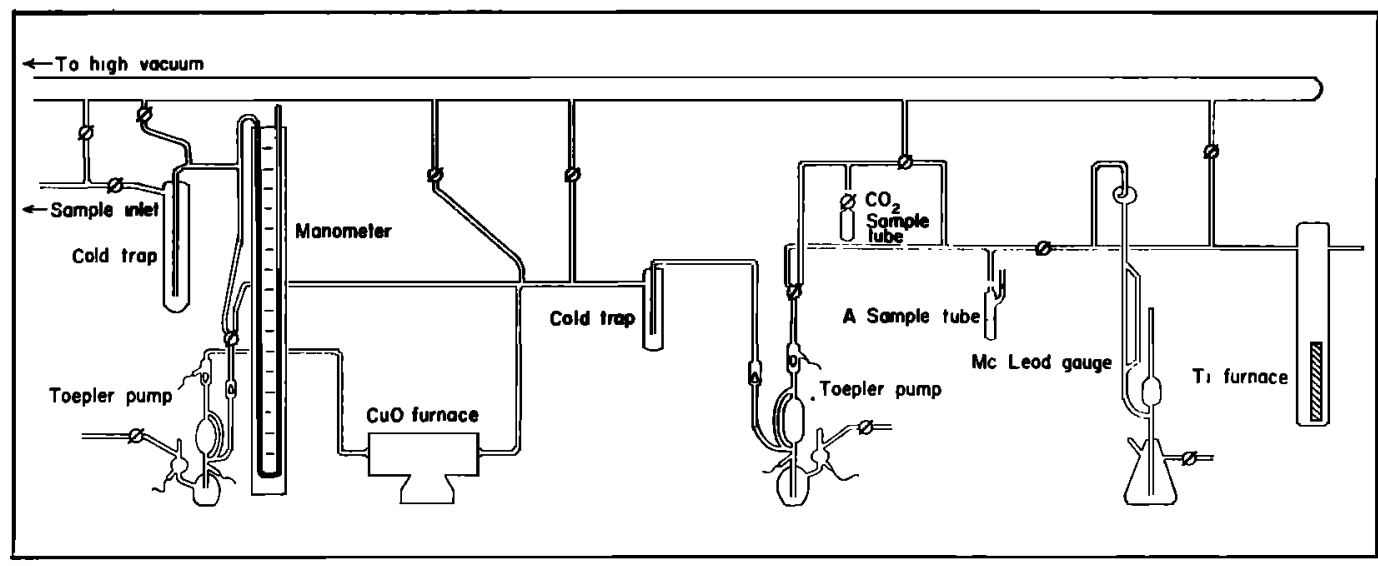

Fig. 1. Vacuum apparatus used for helium, argon, and carbon determination and extraction.

system was found to be vacuum tight, some gas was released into a part of the system of known volume and the pressure measured on a manometer. For most samples a tracer of $A^{38}$ was introduced and the gases mixed. The sample size ranged from 2 to 100 cc STP. For total gas carbon analyses, all gas was then pumped directly into the combustion system. For methane carbon analyses, liquid $\mathrm{N}_{2}$ was placed on a cold trap and the noncondensible fraction was continuously pumped into the combustion system until no gas phase remained. The combustion procedure used was similar to that described by Craig [1953]. A $\mathrm{CuO}$ furnace, made of fused quartz, was heated to $900-950^{\circ} \mathrm{C}$, and the gases were cycled through it until complete combustion to $\mathrm{CO}_{2}$ was obtained. During this combustion period, dry ice baths were placed on a cold trap to collect the water produced. After combustion, the dry ice baths were replaced with liquid nitrogen and the noncondensibles-including $\mathrm{N}_{2}, \mathrm{He}$, and $\mathrm{A}$-were transferred by a Toepler pump into another section of the line (of known volume) containing a Ti furnace, McLeod gages, and a sample tube filled with activated charcoal. The Ti furnace was heated to approximately $950^{\circ} \mathrm{C}$ and the gas sample purified. The amount of this noble gas residue was then measured, using a McLeod gage. Liquid $\mathrm{N}_{2}$ was next applied to the charcoal trap and the condensible fraction quantitatively absorbed. The pressure was again measured and attributed to helium. The argon sample tube was sealed off from the line and mass spectrometrically analyzed. The helium yield was checked by running samples of known helium concentration and by comparing the results of duplicate analyses in which the combustion time and the amounts of gas were varied by a factor of 4 . The purity was checked by observing the Tesla discharge color. No detectable loss of helium by diffusion through the fused quartz combustion tubes was observed. According to the work of Norton [1953] on the diffusion of helium through fused quartz at various temperatures, it was expected that less than 1 per cent of the helium would be lost by diffusion during the combustion procedure. Blank runs carried out under conditions similar to those in which a sample was being analyzed showed no appreciable introduction of inert gases into the line.

The argon content was determined by (1) the difference between the volumetrically determined total noble gas residue and the helium content, (2) a volumetric determination of the condensible fraction after a second purification (before which the helium was pumped off and the Ti furnace outgassed), and (3) isotope dilution using $A^{\text {ss }}$ tracers of known content as described by Wasserburg and Hayden [1955]. The volumetrically determined argon values are generally higher than the isotope dilution value. The first method yields argon contents up to 40 per cent higher than the isotope dilution value, whereas the second method shows discrepancies of up to 15 per cent. The results obtained by the first method were highly reproducible over a long period of time. They were, nevertheless, frequently in error, presumably owing to the 


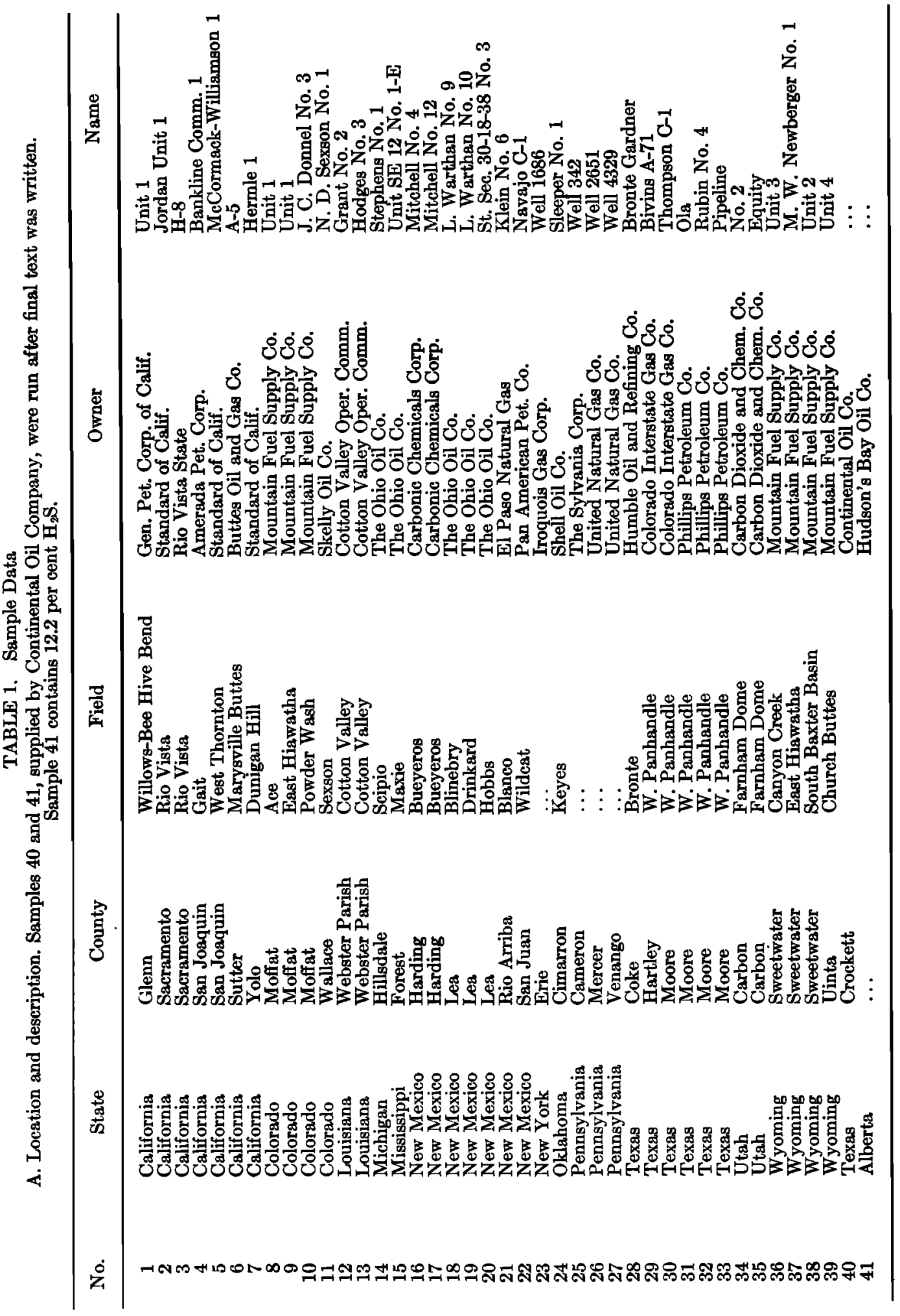




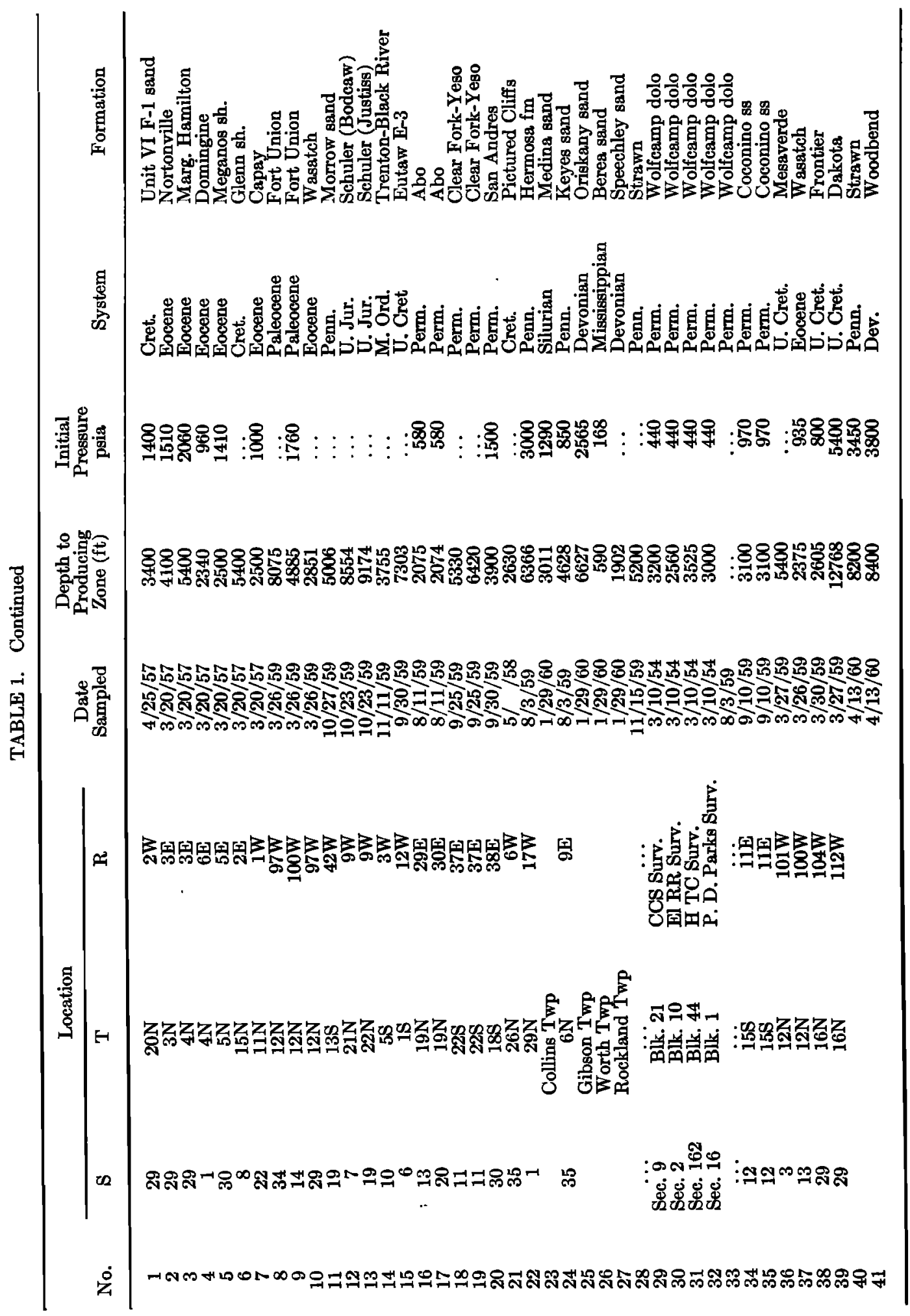


TABLE 1. Continued

B. Analytical data

\begin{tabular}{|c|c|c|c|c|c|c|c|}
\hline No. & $\begin{array}{l}\text { Lithology of } \\
\text { producing zone }\end{array}$ & $\mathrm{CH}_{4} \%$ & $\mathrm{C}_{2} \mathrm{H}_{6} \%$ & $\mathrm{~N}_{2} \%$ & $\mathrm{CO}_{2} \%$ & He ppm & A ppm \\
\hline $\begin{array}{r}1 \\
2 \\
3 \\
4 \\
5 \\
6 \\
7 \\
8 \\
9 \\
10 \\
11 \\
12 \\
13 \\
14 \\
15 \\
16 \\
17 \\
18 \\
19 \\
20 \\
21 \\
22 \\
23 \\
24 \\
25 \\
26 \\
27 \\
28 \\
29 \\
30 \\
31 \\
32 \\
33 \\
34 \\
35 \\
36 \\
37 \\
38 \\
39 \\
40 \\
41\end{array}$ & $\begin{array}{c}\text { ss } \\
\text { ss } \\
\text { ss } \\
\text { ss } \\
\text { ss } \\
\text { ss } \\
\text { ss } \\
\text { ss } \\
\text { ss } \\
\text { ss } \\
\text { ss } \\
\text { ss } \\
\text { ss } \\
\text { lms } \\
\text { s8 } \\
\text { sh and se } \\
\text { sh and ss } \\
\text { ss } \\
\text { ss } \\
\text { lms } \\
\text { ss } \\
\text { lms } \\
\text { ss } \\
\text { ss } \\
\text { ss } \\
\text { ss } \\
\text { ss } \\
\text { ss and lms } \\
\text { dolo } \\
\text { dolo } \\
\text { dolo } \\
\text { dolo } \\
\text { dolo } \\
\text { ss } \\
\text { ss } \\
\text { ss } \\
\text { sg } \\
\text { ss } \\
\text { ss } \\
\text { lms reef } \\
\text { lms reef }\end{array}$ & $\begin{array}{c}98.16 \\
95.43 \\
95.12 \\
68.91 \\
96.20 \\
90.70 \\
97.32 \\
84.5 \\
90.5 \\
86.7 \\
53.5 \\
82.7 \\
75.1 \\
56.1 \\
96.52 \\
0.0 \\
0.0 \\
82.58 \\
82.4 \\
86.3 \\
91.10 \\
38.0 \\
86.2 \\
65.3 \\
97.5 \\
95.1 \\
75.7 \\
76.5 \\
73.8 \\
84.0 \\
90.32 \\
90.42 \\
72.2 \\
0.0 \\
0.0 \\
86.2 \\
88.4 \\
94.9 \\
89.8 \\
72.6 \\
71.1\end{array}$ & $\begin{array}{c}0.13 \\
2.37 \\
3.96 \\
0.01 \\
0.04 \\
0.11 \\
0.01 \\
10.5 \\
5.3 \\
11.01 \\
6.6 \\
14.8 \\
23.2 \\
21.4 \\
1.06 \\
0.0 \\
0.0 \\
15.36 \\
14.8 \\
10.0 \\
7.87 \\
10.6 \\
8.0(1) \\
6.7 \\
2.0(1) \\
2.8(1) \\
23.6(1) \\
15.9 \\
9.6(1) \\
6.4 \\
.13 \\
11.8 \\
11.8 \\
0.0 \\
0.0 \\
9.4 \\
10.3 \\
5.4 \\
7.0 \\
24.2 \\
7.9 \\
\end{array}$ & $\begin{array}{c}1.60 \\
1.57 \\
0.86 \\
30.97 \\
3.76 \\
9.15 \\
2.65 \\
4.03 \\
2.40 \\
2.30 \\
36.6 \\
1.0 \\
0.87 \\
22.2 \\
1.48 \\
0.12 \\
0.15 \\
1.98 \\
2.6 \\
3.4 \\
0.94 \\
42.5 \\
5.6 \\
24.9 \\
0.50 \\
1.9 \\
0.64 \\
6.5 \\
16.6 \\
8.95 \\
9.7 \\
9.6 \\
15.2 \\
0.60 \\
0.55 \\
2.08 \\
1.22 \\
1.8 \\
3.09 \\
2.5 \\
3.6\end{array}$ & $\begin{array}{c}0.11 \\
0.09 \\
0.06 \\
0.09 \\
0.00 \\
0.03 \\
0.02 \\
1.03 \\
1.82 \\
0.57 \\
1.52 \\
0.77 \\
0.1 \\
0.90 \\
99.9 \\
99.8 \\
0.05 \\
0.17 \\
0.25 \\
0.07 \\
2.1 \\
\ddot{0.7} \\
\ldots . \\
\ldots . \\
0.9 \\
\ddot{0} .1 \\
\ldots . \\
0.0 \\
09.3 \\
99.3 \\
2.29 \\
0.10 \\
0.85 \\
0.85 \\
0.6 \\
5.0\end{array}$ & $\begin{array}{c}47.5 \\
41.2 \\
37 \\
96.6 \\
101 \\
37.6 \\
85 \\
101 \\
63 \\
140 \\
26000 \\
152 \\
151 \\
1350 \\
359 \\
44.5 \\
46.6 \\
348 \\
480 \\
69.4 \\
172 \\
62200 \\
1640 \\
22600 \\
203 \\
1575 \\
805 \\
1720 \\
9370 \\
4180 \\
4480 \\
4170 \\
7000 \\
232 \\
187 \\
75 \\
158 \\
757 \\
152 \\
593 \\
1670\end{array}$ & $\begin{array}{c}57.4 \\
52.2 \\
67 \\
140 \\
88.2 \\
53.1 \\
125 \\
32 \\
39 \\
118 \\
1400 \\
26.5 \\
42.0 \\
360 \\
81.9 \\
28.0 \\
29.2 \\
57.3 \\
66.8 \\
117 \\
46.1 \\
5630 \\
77.1 \\
1080 \\
6.8 \\
35.8 \\
14.9 \\
376 \\
877 \\
470 \\
482 \\
461 \\
710 \\
79.5 \\
65.4 \\
27 \\
73.4 \\
66.8 \\
17.5 \\
117 \\
418\end{array}$ \\
\hline
\end{tabular}

${ }^{1}$ Includes $\mathrm{CO}_{2} ;{ }^{2}$ Includes $\mathrm{C}_{2} \mathrm{H}_{6}$ and higher carbons, and $\mathrm{CO}_{2}$.

presence of contaminating gases. A second purification as described in (2) gave volumetric values in relatively good agreement with (3). All samples except $3,7,8,9,10$, and 36 have been run by isotopic dilution, and, except for these samples, the values for argon content listed in Table 1 have been determined by isotope dilution. After the noncondensibles were pumped out of the part of the line containing the $\mathrm{CuO}$ furnace, the liquid nitrogen baths that hold $\mathrm{H}_{2} \mathrm{O}$ and $\mathrm{CO}_{2}$ were again replaced by dry ice baths and the $\mathrm{CO}_{2}$ was allowed to sublime into this part of the line. The $\mathrm{CO}_{2}$ was then transferred into a sample tube for isotopic analysis.
The carbon dioxide in the natural gases was removed by placing liquid nitrogen on a cold trap and pumping off the noncondensibles through another cold trap in order to retain any $\mathrm{CO}_{2}$ that might be lost from the first trap. The remaining gases, which include $\mathrm{CO}_{2}$ and hydrocarbons less volatile than $\mathrm{CH}_{4}$, were then transferred into a reaction vessel containing a saturated $\mathrm{Ba}(\mathrm{OH})_{2}$ solution with 80 per cent phosphoric acid in a side arm. The $\mathrm{CO}_{2}$ was then converted to the carbonate, and the hydrocarbons were pumped off. The carbonate was reconverted to $\mathrm{CO}_{2}$ by reaction with phosphoric acid and the $\mathrm{CO}_{2}$ transferred to a vessel with liquid nitrogen. 
TABLE 1. Continued

B. Analytical data

\begin{tabular}{|c|c|c|c|c|c|c|c|c|c|}
\hline No. & $\begin{array}{l}\mathbf{A}_{\text {rad }} \\
\text { ppm }\end{array}$ & $\begin{array}{l}\mathrm{A}_{\mathrm{gir}} \\
\mathrm{ppm}\end{array}$ & $\in \%$ & $\mathrm{He} / \mathrm{A}_{\mathrm{rad}}$ & $A^{40} / A^{26}$ & $A^{38} / A^{36}$ & $\left(\mathbf{N}_{2} / \mathbf{A}_{\text {air }}\right)$ & $f_{A}=$ & $V \cdot / V$ \\
\hline $\begin{array}{r}1 \\
2 \\
3 \\
4 \\
5 \\
6 \\
7 \\
8 \\
9 \\
10 \\
11 \\
12 \\
13 \\
14 \\
15 \\
16 \\
17 \\
18 \\
19 \\
20 \\
21 \\
22 \\
23 \\
24 \\
25 \\
26 \\
27 \\
28 \\
29 \\
30 \\
31 \\
32 \\
33 \\
34 \\
35 \\
36 \\
37 \\
38 \\
39 \\
40 \\
41\end{array}$ & $\begin{array}{c}3.69 \\
3.9 \\
4.4 \\
15.7 \\
4.64 \\
9.47 \\
9.3 \\
11.2 \\
4.8 \\
13.6 \\
1260 \\
15.9 \\
27.2 \\
270 \\
48.2 \\
27.6 \\
29.0 \\
28.2 \\
37.9 \\
28.1 \\
13.4 \\
5580 \\
62.6 \\
969 \\
4.2 \\
17.7 \\
6.0 \\
250 \\
697 \\
375 \\
359 \\
336 \\
518 \\
75.2 \\
60.7 \\
10.0 \\
12.5 \\
59.1 \\
12.2 \\
73.4 \\
381\end{array}$ & $\begin{array}{c}53.7 \\
48.3 \\
63 \\
124 \\
83.6 \\
43.6 \\
116 \\
21 \\
35 \\
104 \\
140 \\
10.6 \\
14.8 \\
90 \\
33.7 \\
0.4 \\
0.2 \\
29.1 \\
28.9 \\
89 \\
32.7 \\
50 \\
14.5 \\
111 \\
2.6 \\
18.1 \\
8.9 \\
126 \\
180 \\
95 \\
123 \\
125 \\
192 \\
4.3 \\
4.7 \\
17 \\
60.9 \\
7.7 \\
5.3 \\
43.6 \\
37\end{array}$ & $\begin{array}{r}6.4 \\
7.5 \\
6.6 \\
11.2 \\
5.3 \\
17.8 \\
7.4 \\
35.0 \\
12.3 \\
11.5 \\
90.0 \\
60.0 \\
64.8 \\
75.0 \\
58.8 \\
98.4 \\
99.3 \\
49.2 \\
56.7 \\
24.0 \\
29.1 \\
99.0 \\
81.3 \\
89.6 \\
61.8 \\
49.5 \\
40.2 \\
66.5 \\
79.3 \\
79.7 \\
74.5 \\
72.9 \\
72.9 \\
94.5 \\
92.7 \\
37.0 \\
17.0 \\
88.4 \\
69.7 \\
62.8 \\
91.1\end{array}$ & $\begin{array}{c}12.9 \\
10.6 \\
8.4 \\
6.15 \\
21.8 \\
3.97 \\
9.2 \\
9.0 \\
13.1 \\
10.3 \\
20.6 \\
9.56 \\
5.55 \\
5.00 \\
7.46 \\
1.61 \\
1.61 \\
12.3 \\
12.7 \\
2.47 \\
12.8 \\
11.1 \\
26.2 \\
23.3 \\
48 \\
89 \\
134 \\
6.88 \\
13.4 \\
11.2 \\
12.5 \\
12.4 \\
13.5 \\
3.09 \\
3.08 \\
7.5 \\
12.6 \\
12.8 \\
12.5 \\
8.09 \\
4.38\end{array}$ & $\begin{array}{c}316 \pm 3 \\
320 \pm 3 \\
317 \pm 3 \\
334 \pm 2 \\
312 \pm 6 \\
361 \pm 2 \\
320 \pm 6 \\
456 \pm 14 \\
337 \pm 2 \\
336 \pm 2 \\
2818 \pm 140 \\
736 \pm 8 \\
841 \pm 12 \\
1185 \pm 12 \\
720 \pm 6 \\
22500 \pm 1100 \\
34000 \pm 4000 \\
587 \pm 3 \\
684 \pm 3 \\
389 \pm 2 \\
417 \pm 2 \\
29100 \pm 4000 \\
1570 \pm 20 \\
2720 \pm 140 \\
775 \pm 30 \\
587 \pm 5 \\
494 \pm 5 \\
883 \pm 10 \\
1435 \pm 14 \\
1465 \pm 15 \\
1160 \pm 12 \\
1100 \pm 11 \\
1195 \pm 11 \\
5300 \pm 120 \\
4150 \pm 95 \\
472 \pm 15 \\
355 \pm 3 \\
2560 \pm 130 \\
960 \pm 24 \\
796 \pm 10 \\
3316 \pm 150\end{array}$ & $\begin{array}{c}0.219 \pm 0.018 \\
0.202 \pm 0.015 \\
\ldots .00 \\
0.196 \pm 0.007 \\
0.195 \pm 0.015 \\
0.194 \pm 0.007 \\
0.201 \pm 0.009 \\
0.195 \pm 0.007 \\
0.195 \pm 0.010 \\
\ldots \\
\ldots \\
\ldots \\
\ldots \\
\ldots \\
\ldots \\
\ldots \\
\ldots \\
\ldots \\
\ldots \\
\ldots \\
\ldots \\
\ldots \\
\ldots \\
\ldots \\
0.197 \\
0 \\
0.201 \\
0.186 \\
0.003 \\
0.014 \\
\ldots \\
\ldots \\
\ldots \\
\ldots \\
0.004 \\
0.203 \\
0.188 \pm 0.010 \\
0.204 \pm 0.024 \\
0.178 \pm 0.018 \\
\ldots \\
\ldots\end{array}$ & $\begin{array}{r}298 \\
325 \\
137 \\
2500 \\
\mathbf{4 5 0} \\
2100 \\
228 \\
\mathbf{1 9 2 0} \\
\mathbf{7 0 6} \\
221 \\
\mathbf{2 6 1 0} \\
\mathbf{9 4 3} \\
\mathbf{5 8 8} \\
\mathbf{2 4 7 0} \\
\mathbf{4 3 9} \\
\mathbf{3 0 0 0} \\
\mathbf{7 5 0 0} \\
6880 \\
\mathbf{9 0 0} \\
\mathbf{3 8 2} \\
\mathbf{2 8 7} \\
\mathbf{8 5 0 0} \\
\mathbf{3 8 6 0} \\
2240 \\
1920 \\
\mathbf{1 0 5 0} \\
720 \\
\mathbf{5 1 5} \\
\mathbf{9 2 2} \\
\mathbf{9 4 2} \\
\mathbf{7 8 9} \\
\mathbf{7 6 8} \\
\mathbf{7 9 2} \\
\mathbf{1 3 9 5} \\
\mathbf{1 1 7 0} \\
1224 \\
200 \\
\mathbf{2 3 4 0} \\
\mathbf{5 8 3 0} \\
\mathbf{5 7 3} \\
\mathbf{9 7 3}\end{array}$ & $\begin{array}{r}0.68 \\
0.69 \\
0.46 \\
0.49 \\
0.50 \\
0.56 \\
0.51 \\
0.68 \\
0.74 \\
0.44 \\
-0.31 \\
0.83 \\
0.74 \\
0.37 \\
0.54 \\
1.00 \\
1.00 \\
0.71 \\
0.65 \\
0.43 \\
0.84 \\
0.36 \\
0.92 \\
0.60 \\
0.97 \\
0.99 \\
0.97 \\
-0.22 \\
0.66 \\
0.82 \\
0.77 \\
0.77\end{array}$ & $\begin{array}{r}25 \\
24 \\
62 \\
55 \\
53 \\
42 \\
51 \\
25 \\
19 \\
67 \\
130 \\
11 \\
19 \\
90 \\
45 \\
0 \\
0 \\
22 \\
29 \\
70 \\
10 \\
94 \\
5 \\
35 \\
1.6 \\
0.6 \\
1.6\end{array}$ \\
\hline
\end{tabular}

The accompanying water was then held with a dry ice bath, and the purified $\mathrm{CO}_{2}$ transferred into a sample vessel and mass analyzed.

In some of the carbon dioxide well samples, hydrocarbons were not detected, and therefore the $\mathrm{CO}_{2}$ was purified by simply pumping off the noncondensibles at liquid nitrogen temperature. The Farnham Dome samples contained considerable amounts of $\mathrm{H}_{2} \mathrm{~S}$, and this was removed by passing the gas repeatedly over heated silver filings.

All of the helium analyses and those argon analyses that were determined by isotopic dilution are most probably accurate to within 10 per cent. The helium was not isotopically analyzed; the argon isotopic composition is given in Table 1 along with the mean deviation of the analysis. $A^{38} / A^{30}$ ratios are given for samples on which a run was made without using a tracer. The total carbon and methane carbon isotopic analyses are reproducible to within 0.2 per mil, and the $\mathrm{CO}_{2}$ carbon analyses are reproducible to within 1 per mil. The isotopic composition of the argon was determined on mass spectrometers at the California Institute of Technology and the University of California at Berkeley. Agreement was good on several samples run by both laboratories. The background was always much lower than the sample peak heights. 
The carbon was analyzed at the California Institute of Technology on a 6-inch mass spectrometer in Dr. Epstein's laboratory. All samples on which carbon isotopic analyses were made were run as carbon dioxide according to the procedure described by McKinney, McCrea, Epstein, Allen, and Urey [1950]. The samples were analyzed relative to Caltech Working Standard II, and then converted to corresponding values relative to the Chicago Standard PDB.

\section{Nitrogen and Atmospheric Argon}

Mass spectrometric analyses of the extracted argon samples showed that while the $A^{40} / A^{36}$ ratios ranged from 312 to 34,000 , the $A^{88} / A^{80}$ ratio was practically constant and was, to within experimental error, equal to the value of 0.187 found in atmospheric argon.

Each sample was found to have an $\mathrm{A}^{40} / \mathrm{A}^{36}$ ratio greater than 295.6, the value for air argon [Nier, 1950]. These gases appear to be mixtures of radiogenic argon $\left(\mathrm{A}_{\mathrm{red}}\right)$ and atmospheric argon $\left(A_{a i r}\right)$. The fraction, $\epsilon$, of the total argon that is radiogenic is given by the expression

$$
\epsilon=\frac{\mathrm{A}_{\mathrm{rad}}}{\mathrm{A}_{\text {total }}}=1-\frac{296.8}{\left(\mathrm{~A}^{40} / \mathrm{A}^{36}\right)_{\mathrm{s}}+1.2}
$$

where $\left(A^{40} / A^{36}\right)$, is the ratio in the sample. ${ }^{1}$ These parameters are presented in Table 1.

It is not possible to say under what conditions the atmospheric argon was introduced into the samples. Air bubbles trapped in the original

1 The formulas used to calculate the amounts of radiogenic $\left(A^{40}\right)$, and total sample $\left(A^{40}\right)$, when a tracer, $t$, was used are:

$$
\begin{aligned}
\left(A^{40}\right)_{r}=\left(A^{38}\right)_{\imath}\left\{\left(\frac{A^{40}}{A^{38}}\right)_{\mu}-\left(\frac{A^{30}}{A^{38}}\right)_{\mu}\left(\frac{A^{40}}{A^{36}}\right)_{n}\right. & \left(\frac{A^{30}}{A^{38}}\right)_{\mu}\left(\frac{A^{38}}{A^{36}}\right)_{n}\left(\frac{A^{40}}{A^{38}}\right)_{t} \\
& -\left(\frac{A^{40}}{A^{38}}\right)_{\mu}\left(\frac{A^{38}}{A^{36}}\right)_{n}\left(\frac{A^{36}}{A^{38}}\right)_{\imath} \\
& \left.+\left(\frac{A^{40}}{A^{36}}\right)_{n}\left(\frac{A^{36}}{A^{38}}\right)_{t}-\left(\frac{A^{40}}{A^{38}}\right)_{\imath}\right\} \\
& 1-\left(\frac{A^{36}}{A^{38}}\right)_{\mu}\left(\frac{A^{38}}{A^{36}}\right)_{n}
\end{aligned}
$$

and sediments, air dissolved in water associated with the sediments, gases brought in at some later time by circulating ground water, and contamination during sampling and analysis are all possible sources. By means of blank runs and repeat analyses, it was possible to show that essentially none of the atmospheric argon was due to contamination from laboratory procedures. Samples were run with atmospheric argon contents as low as $0.2 \mathrm{ppm}$ without any difficulty. Repeat analyses of samples at different times yielded identical $\mathrm{A}^{40} / \mathrm{A}^{36}$ ratios. Inspection of the $A^{40} / A^{86}$ ratios shows that these values tend to be rather constant within certain gas fields. Although some of the samples may possibly have been contaminated during sample collection, it is our conclusion that, for most cases, the atmospheric fractions represent the accumulated air argon associated with these gases during their natural evolution. While the composition and abundance of atmospheric argon may have changed through geologic time, we have assumed the present-day values. It is conceivable that measurements of the $\mathrm{A}^{40} / \mathrm{A}^{\text {as }}$ ratio may prove useful as a tracer in identifying and studying gas reservoir characteristics.

The natural gases analyzed contained amounts of nitrogen varying from 0.1 to 42.5 per cent. Gases composed of essentially 100 per cent nitrogen have been reported in the literature, but we have not been able to obtain such samples. The origin of nitrogen in natural gases has been often discussed [Hoering, 1957; Scalan, thesis, University of Arkansas; Rayleigh, 1939; Rogers, 1921; and Zobell, 1952] in terms of (1) the introduction of atmospheric nitrogen, (2) the release of nitrogen by the bacterial decomposition

$$
\begin{aligned}
\left(A^{40}\right)_{0}=\left(A^{38}\right)_{\imath}\left\{\left(\frac{A^{40}}{A^{38}}\right)_{\mu}-\left(\frac{A^{40}}{A^{38}}\right)_{\imath}\right. \\
\left.+\left(\frac{A^{40}}{A^{38}}\right)_{\mu}\left[\frac{1-\left(\frac{A^{36}}{A^{38}}\right)_{t}\left(\frac{A^{38}}{A^{38}}\right)_{\mu}}{\left(\frac{A^{38}}{A^{36}}\right)_{\mu}\left(\frac{A^{36}}{A^{38}}\right)_{n}-1}\right]\right\}
\end{aligned}
$$

where the subscripts $t, n$, and $\mu$ refer to the appropriate ratio in the tracer, in normal atmospheric argon, and in the sample-tracer mixture, respectively. 
of nitrogen-bearing compounds, (3) the releasc of nitrogen by the inorganic chemical breakdown of organic compounds, and (4) the liberation of inorganic nitrogen from igneous (and metamorphic) rocks.

One of the processes called upon most frequently to explain the presence of nitrogen in well gases is the incorporation of air in the pore space of various reservoir rocks. If air is included in the sediments, they will contain not only $\mathrm{N}_{2}$ but other atmospheric gases as well. Some workers have assumed that when gases have a $\left(\mathrm{N}_{2} / \mathrm{A}\right)$ ratio approximately equal to that in air, the nitrogen is due to atmospheric contamination. It was pointed out by Wasserburg, Czamanske, Faul, and Hayden [1957] for certain high helium gases from the Texas Panhandle that while the total $\left(\mathrm{N}_{2} / \mathrm{A}\right)$ ratios of these gases were approximately equal to the atmospheric value, most of the argon was of radiogenic origin, and the actual $\left(\mathrm{N}_{2} / \mathrm{A}_{\mathrm{air}}\right)$ ratio was about 850 . They concluded, therefore, that most of the nitrogen could not be due to trapped air. Following this approach, we have made a similar calculation of the $\left(\mathrm{N}_{2} / \mathrm{A}_{\mathrm{air}}\right)$ ratio for our samples. The results are given in Table 1 . The ratio is observed to range between 137 and 8500 . The atmospheric ratio of nitrogen to argon is 84 , and the ratio for the dissolved gases in water in equilibrium with the atmosphere at $20^{\circ} \mathrm{C}$ is 38. Although it may be reasonable to postulate simple mechanisms of gas solution and effervescence, which could account for a factor of 2 or 3 change in the atmospheric $\left(\mathrm{N}_{2} / \mathrm{A}_{\mathrm{alr}}\right)$ ratio, most of the gas samples show much higher nitrogen enrichments. Therefore, in most instances only a small fraction of the nitrogen content of these gases reasonably can be attributed to incorporated air.

As will be shown later, the ratio of $(\mathrm{He} / \mathrm{A})_{\mathrm{rad}}$ in all samples investigated in this report had values of $1.6-130$. Such a range in this ratio is believed to be characteristic of all natural gases, and therefore, if a gas shows a $(\mathrm{He} / \mathrm{A})$ ratio of much less than this, it may be assumed, in lieu of an argon isotopic analysis, that the argon is mainly nonradiogenic and has a corresponding amount of atmospheric nitrogen associated with it.

\section{Helium-Argon Ratio}

If essentially all of the helium contained in natural gases is produced by the radioactive disintegration of uranium and thorium, and the radiogenic fraction of the argon by the electroncapture decay of $\mathrm{K}^{40}$, we can make certain theoretical calculations to determine the values to be expected for the radiogenic helium and argon abundances and their ratio $\left(R=(\mathrm{He} / \mathrm{A})_{\mathrm{rad}}\right)$. In order to discuss the abundances of helium and argon observed in natural gases, it is necessary to consider (1) the variation of $\mathrm{He}^{4}$ - and $\mathrm{A}^{40}$ production with time, (2) the natural distribution of uranium, thorium, and potassium in rocks and their distribution among the mineral phases present, (3) the efficiency with which the helium and argon can escape from crystal lattices and become available for accumulation, and (4) the process of gas migration and accumulation into gas reservoirs. The first part of the discussion will be devoted principally to estimates of the $(\mathrm{He} / \mathrm{A})_{\mathrm{rad}}$ ratio. The problem of absolute concentrations and amounts of these noble gases will be treated later.

Because the half-lives of the uranium, thorium, and potassium isotopes are of the order of $10^{\circ}$ years or more, the rates of production of helium and argon are rather constant for the past several hundred million years. For such a time period we obtain the relationships

$$
\begin{aligned}
& N_{\mathrm{He}_{0}} \simeq(1.20 \mathrm{U}+0.29 \mathrm{Th}) \tau \times 10^{-7} \\
& N_{\mathrm{A}} \simeq 3.99 \mathrm{~K} \tau \times 10^{-12}
\end{aligned}
$$

where $N_{\text {Ho }}$ and $N_{\mathrm{A}}$ are the cc STP of helium and argon, respectively, produced by radioactive decay during a time interval of $\tau$ years, and $\mathrm{U}, \mathrm{Th}$, and $\mathrm{K}$ are the weights of uranium, thorium, and potassium in grams. Dividing these equations we see that the ratio $R$ of the accumulated radiogenic gases is given approximately by

$R \simeq\left[(\mathrm{U} / \mathrm{K}) \times 10^{4}(3.0+0.72(\mathrm{Th} / \mathrm{U}))\right]$

which is independent of the time. It can be seen that $R$ is not very sensitive to changes in the $\mathrm{Th} / \mathrm{U}$ ratio as a shift of from 0 to 4 in this quantity only changes $R$ by a factor of 2 . With the exception of several thorium-rich minerals, the $\mathrm{Th} / \mathrm{U}$ ratio is rarely greater than 10 . Using values of $3.5 \mathrm{ppm}, 10 \mathrm{ppm}$, and 2.6 per cent for the average rock concentration of uranium, thorium, and potassium, respectively, we obtain $R \simeq 7$. This is in rough agreement with the average of the observed results (see Table,1). 


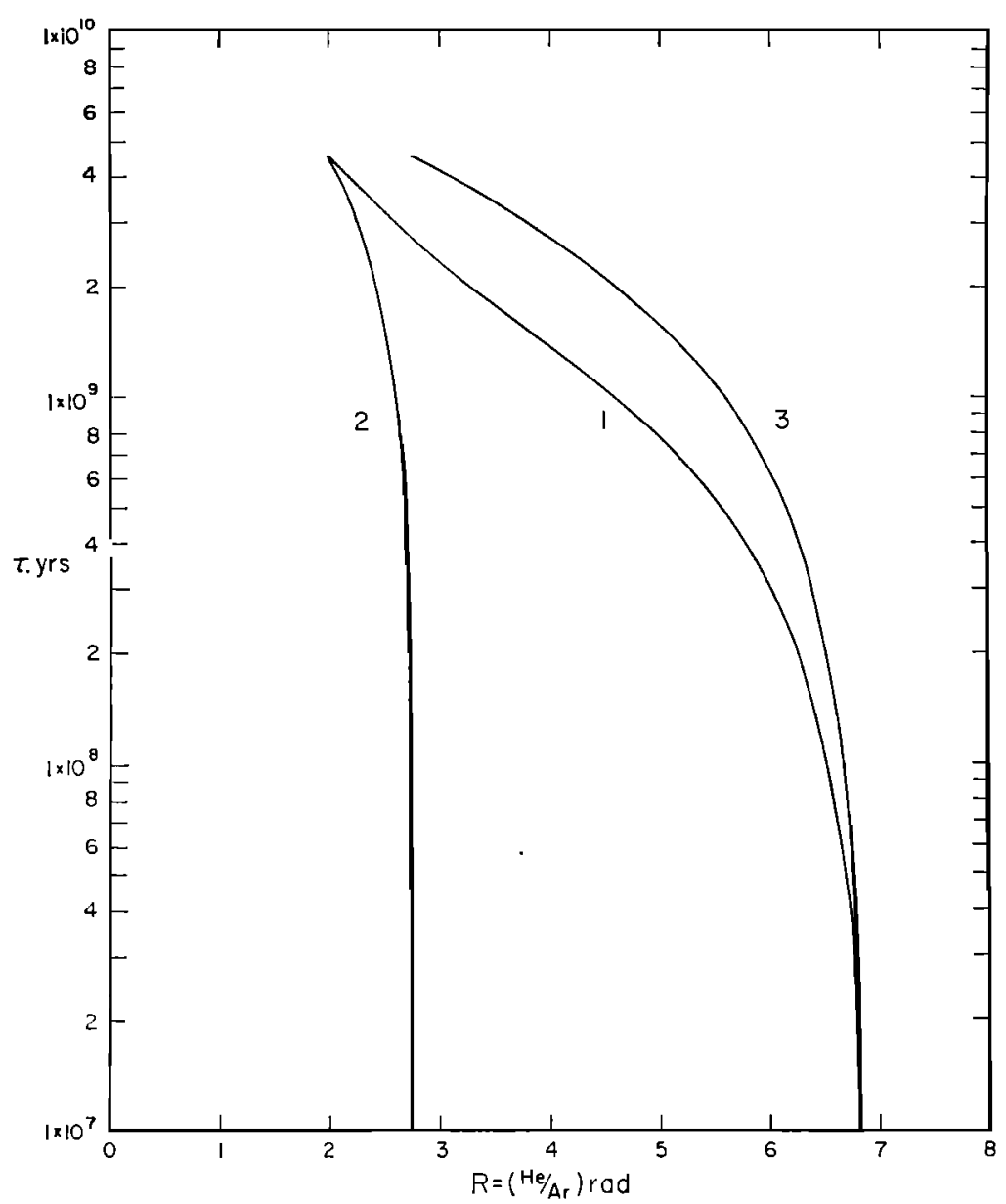

Fig. 2. Variation of $R \equiv(\mathrm{He} / \mathrm{A})_{\text {rad }}$ with time. (1) The ratio $R$ of the production rates at a time $\tau$ years ago. (2) The ratio $R$ of the total gases produced in the interval from a time $4.5 \times 10^{\circ}$ years ago until $\tau$ years ago. (3) The ratio $R$ of the total gases produced in the interval from $\tau$ years ago to the present.

In order to consider the effects of time on $R$ over time intervals longer than a few hundred million years, we have calculated this quantity for the following instances:

1. The ratio $R$ of the production rates at a time $\tau$ years ago.

2. The ratio $R$ of the total gases produced in the interval from a time $4.5 \times 10^{\circ}$ years ago until $\tau$ years ago.

3. The ratio $R$ of the total gases produced in the interval from $\tau$ years ago to the present.

These curves are shown in Figure 2. The previously stated values of uranium, thorium, and potassium were used to represent the present concentrations in an average igneous rock as estimated from selected values in the literature. Inspection of Figure 2 shows that the time dependency of $R$ is rather slight. This ratio changes from 2.0 to 6.8 in the extreme cases considered. Except for the dependency on the $\mathrm{Th} / \mathrm{U}$ ratio, similar curves of this shape are generated by any U/K ratio. They are simply shifted along the abscissa in proportion to the $\mathrm{U} / \mathrm{K}$ ratio. As indicated above, the range in $R$ is a factor of 3.4. If the helium and argon contained in traps in the upper sedimentary crust are composed of locally derived radiogenic material, we would expect the $\left(\mathrm{He}^{4} / \mathrm{A}^{40}\right)_{\mathrm{rad}}$ ratio to be close to the instantaneous value. If thesc 
gases are composed chielly of material in the process of upward transport from the deeper crust and mantle, we might well be dealing with a $\left(\mathrm{He}^{4} / \mathrm{A}^{40}\right)_{\mathrm{rad}}$ ratio somewhere between the instantaneous value and the cumulative ones.

The validity of employing such an 'average' rock as used above is indeed questionable, and

TABLE 2. Carbon isotopic composition of the total gas, $\mathrm{CH}_{4}$, and $\mathrm{CO}_{2}$ contained in some natural gases. Apparent temperatures calculated from $\mathrm{Craig}$ [1953] for the pair $\mathrm{CH}_{4}-\mathrm{CO}_{2}$ are also given. All carbon isotopic data are given as per mil difference in the $\mathrm{C}^{13} / \mathrm{C}^{12}$ ratio between the sample and the Chicago standard, PDB.

\begin{tabular}{|c|c|c|c|c|}
\hline No. & $\delta \cdot$ Total & $\delta_{\mathrm{CH}}$ & $\delta_{\mathrm{CO}}$ & $\begin{array}{l}\text { Calculated } \\
\quad T,{ }^{\circ} \mathbf{C}\end{array}$ \\
\hline 1 & -36.0 & $\cdots$ & $\cdots$ & $\cdots$ \\
\hline 2 & -38.3 & $\ldots$ & $\ldots$ & $\ldots$ \\
\hline 3 & -35.1 & & $\ldots$ & $\ldots$ \\
\hline 4 & & -49.2 & $\ldots$ & $\ldots$ \\
\hline 5 & -57.6 & & $\ldots$ & $\ldots$ \\
\hline 6 & -29.7 & -29.2 & ... & $\ldots$ \\
\hline 7 & -40.2 & & & \\
\hline 8 & -36.7 & -39.2 & -19.5 & 307 \\
\hline 9 & -37.2 & -39.7 & +8.1 & 71 \\
\hline 10 & -40.1 & -43.5 & & \\
\hline 11 & $\ldots$ & -40.3 & -20.9 & 314 \\
\hline 12 & $\ldots$ & -44.1 & -7.9 & 139 \\
\hline 13 & $\ldots$ & -46.4 & -21.9 & 242 \\
\hline 14 & $\ldots$ & -41.6 & & \\
\hline 15 & $\ldots$ & -31.9 & -18.7 & 486 \\
\hline 16 & ... & $\ldots$ & -3.9 & $\ldots$ \\
\hline 17 & ... & . & -4.1 & $\ldots$ \\
\hline 18 & $\ldots$ & -43.6 & ... & $\ldots$ \\
\hline 19 & ... & -44.1 & in & 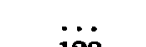 \\
\hline 20 & $\ldots$ & -50.3 & -12.4 & 128 \\
\hline 21 & $\ddot{n}$ & -41.0 & $\ldots$ & \\
\hline 22 & -32.0 & -35.8 & -7.3 & 198 \\
\hline 23 & $\ddot{0}$ & -39.8 & .. & $\ldots$ \\
\hline 24 & -37.5 & & $\cdots$ & .. \\
\hline 25 & $\ldots$ & -34.5 & $\cdots$ & $\cdots$ \\
\hline $\begin{array}{l}26 \\
27\end{array}$ & $-\ddot{43.2}$ & $\begin{array}{l}-49.8 \\
-47.0\end{array}$ & $\cdots$ & $\cdots$ \\
\hline 28 & 20.0 & -41.7 & -19.4 & $\cdots$ \\
\hline 29 & -39.9 & -42.0 & $\ldots$ & $\ldots$ \\
\hline 30 & -38.8 & -40.0 & $\ldots$ & $\ldots$ \\
\hline 31 & -38.5 & $\ldots$ & $\ldots$ & $\ldots$ \\
\hline 32 & -39.6 & $\ldots$ & $\ldots$ & $\ldots$ \\
\hline 33 & -39.2 & ... & $\ldots$ & $\ldots$ \\
\hline 34 & $\ldots$ & ... & -5.0 & $\ldots$ \\
\hline 35 & & 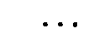 & -5.9 & $\ldots$ \\
\hline 36 & -35.2 & -39.5 & -15.0 & 244 \\
\hline 37 & -38.6 & -40.5 & & \\
\hline 38 & -39.4 & -41.5 & +12.8 & 48 \\
\hline 39 & -37.5 & -38.5 & -8.8 & 185 \\
\hline 40 & $\ldots$ & -45.4 & $\ldots$ & \\
\hline 41 & $\ldots$ & -38.3 & -0.5 & 120 \\
\hline
\end{tabular}

it is necessary to consider in more detail the abundances of the radioactive elements in different rocks. A compilation of the abundances in various lithologies is presented in Table 3. Wide variations in concentrations and $U / K$ and $\mathrm{Th} / \mathrm{U}$ ratios are apparent. For unusual rock types (Kolm from Sweden), or where the rock is the host for a mineral deposit (Colorado Plateau uranium deposits), the ratios may vary over many powers of 10 . Of the normal rock types tabulated, it is seen that the purer carbonates, although not rich in uranium, have very low potassium contents yielding ratios as much as one hundred times greater than granites. On the other hand, an evaporite produced from uncontaminated sea water would yield a U/K ratio one hundred times less, and, in addition, may have a Th/U ratio close to zero. Exclusive of carbonates, however, the normal rock types exhibit a rather constant $U / K$ ratio.

The possible range in the $U / K$ ratio is about 5 powers of 10 in extreme rock types. If some natural processes operate over a sufficiently large scale, they will tend to average over such variations. For example, carbonate rocks are frequently intercalated with shales tending within a given stratigraphic unit to cancel the differences obtaining in the pure lithologies: a 50-50 mixture of a pure limestone and a shale will yield a rather normal $U / K$ ratio. In general, it will be exceedingly difficult to relate the radiogenic helium and argon in any reservoir to a particular rock source, since these gases undoubtedly will have migrated over some distances and through different rock types. In certain instances it may be possible to show that these gases could have been produced within their present reservoir, but this will not be a unique attribute. Considering the wide variations possible in $R$, owing to variations of the $U / K$ ratio, it is remarkable that the measured values lie within such a restricted range. It is our interpretation that this is because of the large- and small-scale averaging inherent in the processes of accumulation with the total source having a 'normal' $\mathbf{U} / \mathbf{K}$ ratio.

One of the important factors concerning the He and $A$ to be investigated is the escape of these gases from the minerals in which they originated. That $A^{40-} K^{40}$ and helium age-dating methods work at all attests to the retention of at least some of these gases in the source minerals. 


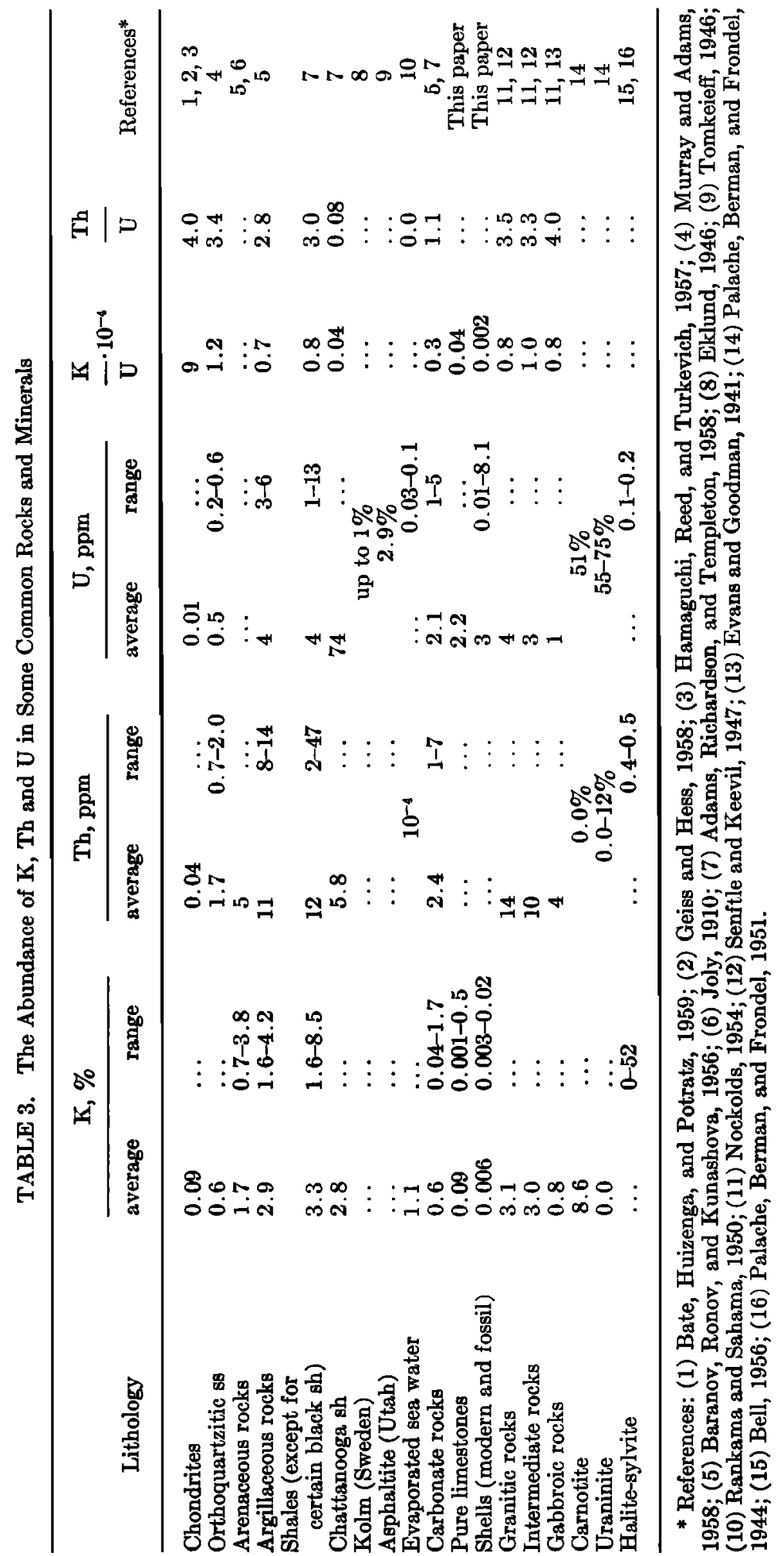


Much work has been done by Keevil [1941] and Hurley and Goodman [1941] on the loss of He from individual minerals and total rock, and corresponding work by Wasserburg, Hayden, and Jensen [1956] and Goldich, Baadsgaard, Nier, and Hoffman [1957] yields some information on the argon retention ability of several common potassium minerals. Some data on $\mathrm{He}$ and $\mathrm{A}$ losses from minerals and rocks are presented in Table 4. Since, in general, the observed helium and argon losses are roughly proportional to the helium and argon contents, respectively, of the mineral, the $\left(\mathrm{He}^{4} / \mathrm{A}^{40}\right)_{\text {rad }}$ ratio of the 'available' gas will be equal to the $\left(\mathrm{He}^{4} / \mathrm{A}^{40}\right)$ production ratio in the total rock multiplied by some constant, which will be taken to be time independent. The value of this constant will be the fractional helium loss, $\xi_{\text {Ho, }}$ divided by the fractional argon loss $\xi_{\mathrm{A}}$. As an approximation we might expect a fresh igneous rock to lose $3 / 5$ its $\mathrm{He}^{4}$ and $1 / 5$ its $\mathrm{A}^{40}$ into interstitial pore spaces. Weathering and diagenetic processes can do little to increase the already high yield for $\mathrm{He}^{4}$ from the rock, but they offer ample opportunity for breaking down potassium-bearing minerals and releasing much retained argon. Thus, we might expect sediments to favor the outgassing of argon more highly than an equivalent fresh igneous rock. The relative rates of escape of helium and argon from rocks at elevated temperatures and pressures are poorly known. However, a more complete loss of both gases might be expected under conditions of metamorphism. If a rock which

TABLE 4. Helium and Argon Retentivity in Some Common Rocks and Minerals*

\begin{tabular}{llc}
\hline & \multicolumn{2}{c}{ Fractional Retentivity } \\
\cline { 2 - 3 } Mineral or Rock & Helium & Argon \\
\hline Quartz & 0.33 & \\
Feldspar & 0.25 & 0.75 \\
Mics & 0.50 & 1.00 \\
Pyroxene & $\mathbf{0 . 7 5}$ & \\
Magnetite & $\mathbf{1 . 0 0}$ & \\
Hornblende & $\mathbf{1 . 0 0}$ & \\
"Granite" & $\mathbf{0 . 4 0}$ & \\
Diabase & 0.60 & \\
\hline
\end{tabular}

* References included Keevil, 1941; Hurley and Goodman, 1941; Wasserburg, Hayden, and Jensen, 1956; and Goldich, Baadsgaard, Nier, and Hoffman, 1957.
TABLE 5. Henry's Law Constants for Several Selected Gases

\begin{tabular}{|c|c|c|c|c|}
\hline \multirow[b]{3}{*}{ Gas } & \multicolumn{4}{|c|}{$\begin{array}{r}K_{i}=C_{i} \sigma / C_{i}^{*} \\
\quad \text { Solvent }\end{array}$} \\
\hline & \multicolumn{2}{|c|}{ Fresh Water } & \multicolumn{2}{|c|}{ Marine Water } \\
\hline & $15^{\circ} \mathrm{C}$ & $50^{\circ} \mathrm{C}$ & $15^{\circ} \mathrm{C}$ & $50^{\circ} \mathrm{C}$ \\
\hline $\mathbf{N}_{2}$ & 56 & 87 & 73 & 114 \\
\hline A & 25 & 40 & 33 & 53 \\
\hline He & 113 & 111 & $\ldots$ & $\ldots$ \\
\hline $\mathrm{CH}_{4}$ & 27 & 46 & $\ldots$ & $\ldots$ \\
\hline
\end{tabular}

has retained 80 per cent of its argon and 40 per cent of its helium is later completely outgassed by metamorphism or fusion, the gas thereby evolved might be preferentially enriched in argon by a factor of 2 . Thus, from an average igneous rock we might expect extreme 'available' $\left(\mathrm{He}^{4} / \mathrm{A}^{40}\right)_{\mathrm{rad}}$ ratios of about 3 and 20 , depending on whether the gases represented the value attained by complete outgassing of a rock which had formerly preferentially lost helium or by the low temperature diffusion of helium and argon out of a young rock. If the source rock differs considerably in its $\mathrm{K}, \mathrm{U}$, and Th abundances from an average igneous rock, the resultant available $\left(\mathrm{He}^{4} / \mathrm{A}^{40}\right)_{\mathrm{red}}$ ratio will, of course, reflect this. Gases originating in pure carbonate rocks may have high values of $R$.

A number of gas transport mechanisms could produce a fractionation of argon and helium. If, during the time of gas accumulation, the helium and argon are transported by solution in connate water, fresh water, or petroleum, the $\left(\mathrm{He}^{4} / \mathrm{A}^{\mathbf{1 0}}\right)_{\mathrm{rad}}$ ratio that we actually observe in a natural gas sample will be influenced by the relative solubilities of these gases in the transporting medium. If diffusive equilibrium is attained, we would expect the following relationship to hold:

$$
R^{\ominus}=\frac{K_{\mathrm{H}}}{K_{\mathrm{A}}} R^{*}=K^{\prime} R^{\bullet}
$$

where $R^{\bullet}$ and $R^{a}$ are the atomic ratios of the helium to argon in solution and in the gas reservoir respectively, and $K_{\mathrm{H}_{0}}$ and $K_{\mathrm{A}}$ are the Henry's law constants for helium and argon, respectively. The Henry's law constants for several gases at various temperatures are given in Table 5. Rakestraw and Emmel [1938] showed 
that argon is only about $\mathbf{8 0}$ per cent as soluble in marine water of normal salinity as it is in fresh water. Similar work by Akerlof [1935] on the effect of salinity on helium solubility suggests about the same behavior for this gas. The solubility of argon and helium in crude petroleum is unknown, as is the importance of noble gas transport by this means. In water solutions for temperatures of $50-80^{\circ} \mathrm{C}, K^{\prime} \simeq 2.8$, and, therefore, the gas phase would be enriched in helium relative to argon as compared with the solution. Thus, if much more gas is contained in solution than occurs in the gas phase, the equilibrium ratio of $\mathrm{He} / \mathrm{A}$ in the gas reservoir would be 2.8 times greater than the 'available' ratio. A more rigorous treatment of this problem is given later in the paper.

The differences in solubility of various natural gas components could in principle, through a multistage process of solution and effervescence, cause considerable variations in $R$. It would be possible under ideal conditions to produce a range in $R$ of over 20 by employing only three stages of distillation. It is not possible at present, however, to say how effective multistage distillation actually is in achieving variations in $R$. That many stages of distillation do not operate is indicated by the limited range observed in $R$.

If compositional variations are ignored, it is seen that the effects of the other parameters will permit over an order of magnitude variation in $R$. Thus, the value of $R$ actually observed in natural gas may range between extremes of at least 3-50 without any need for assuming compositional differences. All of the samples analyzed have values of $R$ that fall within the range of 1.6 to 130 . Most of these results agree quite well with this model, assuming only minor variations in the $U / K$ ratio. It is, of course, possible to attribute the observed variations in $R$ to compositional differences instead of diffusion and solubility effects. It is not possible at present to say precisely which factors account for the variation.

Damon and Kulp [1958] have measured the ratio of excess radiogenic helium to argon in beryls and cordierites. They obtained ratios ranging from 0.5 to 130 with an average value of 20. Our results on well gases are thus rather similar to the values found for these trapped magmatic gases.

It must be pointed out that, with the exception of certain potassium evaporite salts such as sylvite ( $K \simeq 50$ per cent) and some very pure carbonate rocks ( $K<0.01$ per cent), the potassium content of most rocks generally shows less than an order of magnitude variation. This major rock-forming element makes up from 1 to 4 per cent of many sedimentary and igneous rocks. However, uranium and thorium, which generally occur as trace elements, are subject to wide variations in abundance, and the possibility of local enrichments must be considered. Indeed, one of the early theories proposed for the occurrence of high helium wells attributed the high helium content to an underlying uranium deposit [Rogers, 1921]. If an order of magnitude or larger enrichment in the helium content of a natural gas is affected by this process, the gas should show an abnormally high $(\mathrm{He} / \mathrm{A})_{\mathrm{rad}}$ ratio. The large increase in the abundance of a major rockforming element such as potassium as would be needed to maintain the observed $(\mathrm{He} / \mathrm{A})_{\mathrm{rad}}$ ratios could not occur in common rocks. That such an enrichment in radiogenic helium over radiogenic argon does not exist in the case of the Texas Panhandle gas field was shown by Wasserburg, Czamanske, Faul, and Hayden [1957]. The results of the present investigation also tend to disprove the idea of high enrichments in helium due to abnormal uranium or thorium concentrations for a number of high helium gas fields.

The problem of recognizing the contribution of gases from the mantle or lower crust is extremely difficult. This is particularly true for helium and argon, since the earth is a highly differentiated body and the production of these elements is dependent on the $U$, Th, and $K$ concentrations. The ratio $R$ in modern material of chrondritic composition is about 1 ; the ratio $R$ in an average igneous rock 4.5 billion years ago would be 2.0 as compared with the present value of 6.8 .

Some of the lowest values of $\left(\mathrm{He}^{4} / \mathrm{A}^{40}\right)_{\mathrm{rad}}$ were in $\mathrm{CO}_{2}$ wells that are associated with igneous activity. These values are in the direction effected by great age or chondritic production rates. These results, of course, are only suggestive inasmuch as they could be produced by a variety of mechanisms.

It should be noted that the argon from the $\mathrm{CO}_{2}$ wells is extremely radiogenic. If this represents juvenile argon, it indicates that very little $A^{\text {se }}$ is associated with it. This is compatible with 
the results derived from the solubility model for air argon. The latter data indicate that no significant amount of atmospheric type argon occurs in these gases above the amount that would be present from original equilibration with air. We infer from this that no deep-seated gases are contributing significant amounts of argon of this composition.

\section{Noble Gas abundances in Natural Gases}

The helium content of the gas samples investigated varies between 37 and 62,200 ppm and the radiogenic argon content varies between 3.7 and $5580 \mathrm{ppm}$. Since any attempt to explain the occurrence of the rare gases in natural gases must account for the absolute amounts and concentrations as well as for the ratio of radiogenic helium to radiogenic argon, factors influencing helium and argon abundances will now be discussed.

Whereas the $(\mathrm{He} / \mathrm{A})_{\mathrm{rad}}$ ratio is only weakly time-dependent over times comparable to the age of the earth, the actual production of these gases is strongly time-dependent. The radiogenic helium and argon content of a natural gas reservoir is not necessarily proportional to the age of the source rock, but is, rather, a complicated function of the accumulation history of the gas. It is possible that much of the radiogenic gases are incorporated into the natural gas by a sweeping-up effect during the time of migration from the source to the reservoir rock. In such an event, the $\mathrm{He}$ and $\mathrm{A}$ content of the rocks at the time that they were traversed by the accumulating gases would be an important factor. If there was little noble gas escape before gas migration, the length of time between rock formation and petroleum accumulation would determine the concentration of $\mathrm{He}$ and $\mathrm{A}$ in the pore space. Studies of a number of oil and gas fields have shown that this time between source rock deposition and petroleum migration may vary from between tens of millions and hundreds of millions of years. The outgassing of very old basement rocks through metamorphism would be a possible source of high concentrations of these radiogenic gases. Such gases may leak into a sedimentary section through various fractures or faults. It may also be true for some cases that the noble gases have escaped continuously from the rocks during all times except the period of gas accumulation. In this event, the important time factor would be the length of the time interval over which gas migration took place.

Once the gases have been removed from the crystal lattices they become available for migration either by solution or by gaseous transfer. Under equilibrium conditions, the distribution of any gas between a gaseous and liquid phase is related approximately by Henry's law. It is, of course, questionable that equilibrium conditions prevail over large distances between the accumulated gases and interstitial pore fluids. It will, however, be assumed in the following discussion that diffusive equilibrium obtains for the rare gases and the consequences of such a model will be investigated.

Equilibrium model. Goryunov and Kozlov [1940] have pointed out the importance of solubility phenomena in natural gas accumulation, and part of the following discussion parallels their work.

Let us consider an equilibrium reservoir model in which the rock has a porosity $p$, and suppose the pore space to be occupied by both an aqueous phase (s) and a gas phase $(g)$, all under a hydrostatic pressure of $P$ atmospheres. Let the volumes occupied by the gas and aqueous phase be $V \circ$ and $V \cdot$, respectively, and the concentrations of gas species $i$ in each of these phases be $C_{i}{ }^{\theta}$ and $C_{i}{ }^{*}$, in units of standard cc per $\mathrm{cm}^{3}$. The total amount of species $i$ in the pore system is then $C_{i}{ }^{o v}+C_{i} \cdot V^{\circ}$, and the fraction $f_{i}{ }^{\circ}$ of this species in the gas phase is

$$
f_{i}^{0}=\frac{C_{i}{ }^{0} V^{g}}{C_{i}{ }^{g} V^{0}+C_{i}{ }^{g} V^{0}}
$$

Suppose that each species satisfies a Henry's law relationship of the form $C_{i}{ }^{g}=K_{i} C_{i}{ }^{\text {o where }}$ $K_{i}$ is the Henry's law constant for species $i$. We then have

$$
\begin{aligned}
f_{i}^{*}=V^{0} /\left(V^{v}\right. & \left.+\frac{V^{*}}{K_{i}}\right) \\
& =1 /\left(1+\frac{V^{*}}{K_{i} V^{0}}\right)
\end{aligned}
$$

Since $K_{\mathrm{H}_{0}} \simeq 110$ and $K_{\mathrm{A}} \simeq 40$ for aqueous solutions at $50^{\circ} \mathrm{C}, f_{\mathrm{He}^{0}}$ and $f_{\mathrm{A}^{*}}$ will be close to 1 when more than about 5 per cent of the pore space is occupied by a gaseous phase.

In the units used, $C_{i}{ }^{*}$ is (assuming ideality) numerically equal to the partial pressure in 
atmospheres of species $i$. The condition that a pure gas phase $i$ exists when the hydrostatic pressure is $P$ is $P / K_{i}=C_{i}{ }^{\text {s }}$. It follows that for any given concentration $C_{i}{ }^{\bullet}$ there is a maximum depth at which a gas phase of pure $i$ may exist. If we consider an infinitesimal helium bubble at 1000-foot depth under a hydrostatic pressure of 30 atmospheres pressure, this will require $C_{\mathrm{Ho}^{\circ}} \simeq 0.3$ cc $\mathrm{STP} / \mathrm{cc}$ pore vol. If we assume the porosity to be as low as $10^{-2}$, this will correspond to $3 \times 10^{-3} \mathrm{cc}$ STP of He per cc of rock. As will be shown later, such a value is obtainable only under extreme conditions. It is, of course, obvious that if, in a certain environment, radiogenic helium had associated with it another component not subsequently removed, we would not find a pure helium gas.

If we let $C_{i}$ equal the mean concentration of gas species $i$ in the total pore space of the system, then, from (6) we have

$$
C_{i}{ }^{\circ}=C_{i}\left[K_{i}-\left(K_{i}-1\right) f_{i}{ }^{\circ}\right]
$$

From (7) we see that if all of the gas species $i$ occurs in the gas phase the mean concentration will simply equal the concentration in the gaseous phase. If, however, because of the rather insoluble nature of some gases, we have most of the gas dissolved in an aqueous phase with only a very small gas bubble in equilibrium with it $\left(f_{i}^{\circ} \simeq 0\right)$, we gain a factor of $K_{i}$ in $C_{i}$ over the mean pore space concentration. Thus, an infinitesimal bubble of helium in equilibrium with a liquid at $50^{\circ} \mathrm{C}$ will have a $\mathrm{He}$ concentration of 110 times higher than the new concentration. As will be shown below, most reservoir gases appear to have significant amounts of gas in a dissolved phase.

The previous model has treated only a gas with an aqueous phase. For gases associated with a liquid petroleum phase, the equilibrium relationship involving this phase in addition to an aqueous and a gaseous phase must be considered. This will obviously increase the number of variables in the model caluclations. The effect of water salinity must also be taken into account in a more precise calculation.

In addition to the radiogenic noble gas content of natural gases, argon having the composition of present-day atmospheric argon is found to be present in all of the gas samples. As discussed previously, the origin of this air argon is uncertain. For purposes of discussion, we assume it to be due to the release from connate or ground waters which were originally saturated with argon under atmospheric conditions. If the system is closed subsequent to burial, we have

$$
\begin{aligned}
C_{a}{ }^{s 0} V^{s 0}=C_{a}{ }^{o} V^{s}+ & C_{a}{ }^{g} V^{g} \\
& =C_{a}{ }^{a}\left(V^{o}+\frac{V^{s}}{K_{\mathrm{A}}}\right)
\end{aligned}
$$

where the subscript $a$ represents air argon. $C_{a}{ }^{a \theta}$ is the initial concentration of air argon in solution and $V^{\prime 0}$ is the initial volume of the solution. If we assume that the volumes of the initial and final water bodies are equal, we obtain

$$
\frac{V^{s}}{V^{0}}=\frac{C_{a}{ }^{8} K_{\mathrm{A}}}{K_{\mathrm{A}} C_{a}^{s 0}-C_{a}{ }^{0}}
$$

In a diffusive equilibrium model, the system is assigned values of $V^{*}$ and $V o$. This is, of course, unrealistic, since the natural system will not have sharply defined boundaries. The ratio $V \cdot / V^{\circ}$ as calculated will therefore apply for some effective volume over which equilibrium is attained. Under atmospheric conditions at $15^{\circ} \mathrm{C}$ and in equilibrium with ocean water of normal salinity, we have $C_{\mathrm{a}}{ }^{\mathrm{s0}} \simeq 3.0 \times 10^{-4} \mathrm{cc} \mathrm{STP} / \mathrm{cc}$ $\mathrm{H}_{2} \mathrm{O}$ [Rankama and Sahama, 1950]. The value of $C_{a}{ }^{o}$ is determined by the measured concentration of air argon in the natural gas at the well pressure. Substituting this expression for $V \cdot / V^{\circ}$ in (6), and using $K_{\mathrm{A}}=53$ (for $50^{\circ} \mathrm{C}$ and normal marine salinity) we have for radiogenic argon

$$
\begin{aligned}
& f_{\mathrm{A}}{ }^{\circ}= \frac{1}{1+\frac{V^{\circ}}{K_{\mathrm{A}} V^{0}}} \\
& \quad=1-\frac{C_{a}{ }^{\circ}}{K_{\mathrm{A}} C_{a}{ }^{80}} \simeq 1-63 C_{a}{ }^{\circ}
\end{aligned}
$$

and for other arbitrary species

$$
f_{i}^{0}=\frac{1}{1+\frac{C_{a}^{0} K_{\mathrm{A}}}{K_{\mathrm{a}}\left(K_{\mathrm{A}} C_{a}^{{ }^{B} 0}-C_{a}{ }^{g}\right)}}
$$

We see that for the assumed equilibrium model it is possible to calculate the fraction of species $i$ which is in the gas phase. This may be applied to other gases as well as to radiogenic He and $A$. In Table 1 are given the calculated values of $V \bullet / V^{o}$ and $f_{\mathrm{A}}$ for the fraction of radiogenic argon occurring in the gaseous phase. Because of the many obvious uncertainties 
regarding the assumptions involved, it is doubtful that the calculations are strictly applicable to real natural gas reservoirs. Nonetheless, such considerations are useful as a means of comparing the behavior of natural systems to the simple idealized model. Usually the calculated values of $f_{\mathrm{A}}^{g}$ and $V \cdot V o$ appear to be quite reasonable. Only two samples (11 and 24) give impossible values of $f_{\mathrm{A}}{ }^{o}$, and these discrepancies are not extreme.

If there were originally entrapped air bubbles in the pore space, or if $V^{\circ}<V^{\circ 0}$ was due to hydration reactions in diagenesis, then the calculated value of $V \cdot / V^{\circ}$ in (9) will be larger than the true value. The calculated values of $f_{i}$ o will be too small, owing to such effects.

Next, let us look at the effect of porosity, $p$, on concentration. If we assume the mean noble gas concentration in the pore space, $C_{i}$, to be essentially proportional to tho $N_{i}$, noble gas concentration produced in the mineral phase per cc of rock, we have

$$
C_{i}=\frac{\xi_{i}}{p} N_{i}
$$

where $C_{i}$, as before, has the units of cc STP/ce of pore space, $N_{i}$ has the units of cc STP/cc of system, and $\xi_{i}$ is the rock degassing factor. The concentration of the noble gases in the pore space is inversely proportional to the porosity. $N$, for radiogenic helium and argon is given by (2a) and (2b), respectively, calculated per cc of rock. The molecular abundance in $\mathrm{ppm}$ of species $i$ in the gas phase is $\Gamma_{i}$,

$$
\Gamma_{i}=\frac{C_{i}{ }^{0}}{P} \times 10^{6}
$$

where $P$ is the pressure of the reservoir in atmospheres. This equation assumes the gases to be perfect. For hydrostatic pressure $P \simeq$ $0.030 h$, where $h$ is reservoir depth in feet below the surface.

Combining (2), (7), (12), and (13), we have

$$
\begin{array}{r}
\Gamma_{\mathrm{H}_{0}}=\frac{\xi_{\mathrm{He}}(0.120 \mathrm{U}+0.029 \mathrm{Th}) \tau}{P \cdot p} \\
\cdot\left(K_{\mathrm{He}}-\left[K_{\mathrm{He}}-1\right] f_{\mathrm{H}_{\mathrm{e}}}\right) \\
\Gamma_{\mathrm{A}}=\frac{\xi_{\mathrm{A}}\left(3.99 \times 10^{-6} K\right) \tau}{P \cdot p} \\
\cdot\left(K_{\mathrm{A}}-\left[K_{\mathrm{A}}-1\right] f_{\mathrm{A}}\right)
\end{array}
$$

All the parameters given in (14) are expressed as the effective values for the system under investigation. Substitution of reasonable estimates for these parameters yields radiogenic helium and argon concentrations in natural gases quite consistent with actually observed values. For example, let us calculate the radiogenic helium and argon content of two extreme reservoir cases. Let us assume a rock density of $\mathbf{2 . 5}$ and an effective $U, T h$, and $K$ concentration in the rocks of $3.5 \mathrm{ppm}, 10 \mathrm{ppm}$, and 2.6 per cent, respectively. In the one instance, let us set $\tau=5 \times 10^{\mathrm{\theta}} \mathrm{yr} ., \xi_{\mathrm{He}}=\xi_{\mathrm{A}}=1, f_{\mathrm{He}^{0}} \simeq f_{\mathrm{A}^{0}} \simeq 0$, $P=10$ atmospheres (147 psia), and $p=1$ per cent. This corresponds to an environment in which the total radiogenic noble gas content produced by one-half billion years of decay is completely released into rock of 1 per cent mean porosity having a hydrostatic pressure of 10 atmospheres. Geologically, this could be brought about by the continuous release of radiogenic gases into overlying sediments of one-half billion-year age, or by the complete retention of such gases in basement rocks over this time interval, followed by some metamorphic event which then released the gas. This former possibility would appear unlikely where no sedimentary cover of sufficient age was present to trap the continuously released gas. The gas is virtually all dissolved in an aqueous phase, and thus the concentration in the gas phase is increased over the mean pore space concentration by the numerical value of the Henry's law constant. These conditions yield $\Gamma_{\mathrm{H}_{0}} \simeq 10^{\circ} \mathrm{ppm}$ and $\Gamma_{\mathrm{A}} \simeq 5 \times 10^{4} \mathrm{ppm}$.

For contrast, let us consider a case in which $\tau=5 \times 10^{7}$ years, $\xi_{\mathrm{H}_{\mathrm{o}}} \simeq \xi_{\mathrm{A}} \simeq 0.5, f_{\mathrm{He}^{g}} \simeq f_{\mathrm{A}}{ }^{\circ} \simeq 1$, $P=100$ atmospheres (1470 psia), and $p=5$ per cent. This corresponds to a situation in which one-half of the radiogenic noble gas production over a 50-million-year period is released into rock of 5 per cent mean porosity having a hydrostatic pressure of 100 atmospheres. These conditions yield $\Gamma_{\mathrm{H}_{\theta}}=10 \mathrm{ppm}$ and $\Gamma_{\mathrm{A}}=1 \mathrm{ppm}$. If, instead, the gas were mainly dissolved $(f \sim 0)$, the value of $\Gamma_{\mathrm{He}}$ would become a factor of 100 larger.

An average reservoir might have effective values of $\tau=10^{\mathrm{s}}$ years, $\xi_{\mathrm{He}}=4 / 5, \xi_{\mathrm{A}}=1 / 2$, $f_{\mathrm{H}^{\circ}}{ }^{\circ} \simeq 0.9, f_{\mathrm{A}^{0}} \simeq 0.75, P=50$ atmospheres (735 psia), and $p=3$ per cent. Assuming the same $U$, Th, and $\mathrm{K}$ abundances and rock density 
as above, we have $\Gamma_{\mathrm{H}_{0}}=1040 \mathrm{ppm}$ and $\Gamma_{\mathrm{A}}=$ $86 \mathrm{ppm}$ with $R \simeq 12$. In this case we have 80 per cent and 50 per cent of the accumulated radiogenic helium and argon, respectively, resulting from one hundred million years of decay being released into rock of 3 per cent mean porosity. The values of $f_{i}{ }^{0}$ correspond to having $V^{\prime} / V^{\circ} \simeq 10$

In order to make an estimate of the volume of rock swept out during the formation of a gas reservoir, let us consider the helium-producing zone of the Rattlesnake Gas Field, San Juan County, New Mexico. W. M. Deaton, chief helium consultant for the Bureau of Mines Helium Activity (personal communication) estimates the total original volume of the reservoir gas to be about $2.4 \times 10^{\circ}$ cubic feet at $15.0 \mathrm{psia}$ and $60^{\circ} \mathrm{F}$. About half of the total gas has been removed, and the field is not being produced at the present time. The gas, which has a helium content of 7.6 per cent, was produced from the Leadville-Ouray (Mississippian-Devonian) formations and had an initial pressure of about 3000 psia. Thus the reservoir is approximately $1.2 \times 10^{7}$ cubic feet, and assuming $p=2$ per cent and $V^{\circ} / V^{\circ} \simeq 94$ (approximate values of near-by Navajo C-1), we see that this corresponds to a volume of $V \% / p$ of $5.6 \times 10^{10}$ cubic feet, or 0.4 cubic mile. Assuming an average uranium and thorium abundance in the rock $\xi_{\mathrm{H}_{0}}=1$, and an effective $\tau$ of $3 \times 10^{8}$ years, we calculate from (14) that $\Gamma_{\mathrm{B}_{0}} \simeq 7000 \mathrm{ppm}$. This is lower than the observed value by a factor of 10 . Let us now look at some possible explanations for this discrepancy. Since the gas has a $(\mathrm{He} / \mathrm{A})_{\mathrm{rad}}$ ratio which is characteristic of common rocks, we cannot reasonably assume that either the uranium or thorium concentrations, or both, in this source are abnormally high, although a factor of 2 increase may well occur. Although the gas reservoir is in Pennsylvanian strata, it is possible that the radiogenic fraction of the gas was chiefly derived by the outgassing of much older basement rock containing a correspondingly higher helium concentration. Also, the possibility that our equilibrium solubility model is incorrect would allow for a twofold increase in the helium concentration in the gas phase above that calculated. A favorable combination of these three effects could just allow for the observed helium concentration in the gas. In addition, it is possible that whereas the porosity of the reservoir rock is 2 per cent, the effective porosity of the entire source rock system is much lower. This might be expected if most of the helium were derived from a very tight basement complex. It is difficult to tell which are governing factors in this case. At present, we surmise that this gas has probably been produced by the favorable conjunction of several of these effects. It should be emphasized that it is rather difficult to account for this factor of 10 ; if an additional factor of 10 were required, it would be impossible to obtain this reasonably in terms of the present model.

If we compare the San Juan high helium gas with that from the Texas Panhandle, we see that the former gas not only contains more than a fivefold higher abundance in helium, but also a 35 times greater helium concentration, due to the higher pressure of the San Juan gas.

It should be pointed out that a gas that existed at rather shallow depths with a particular abundance of helium and subsequently transported as a closed system to a great depth will retain the same helium abundance, but it will have a much higher helium concentration. Such a gas will, of course, not be in equilibrium with the surrounding aqueous reservoir and will ultimately return to a lower helium concentration. There is no evidence supporting such a transportation history for the San Juan gas.

We have seen that under equilibrium conditions the concentration of a slightly soluble gas such as $\mathrm{He}$ or $\mathrm{A}$ in the gaseous phase is of the order of $10^{2}$ times its concentration in solution. The uniform release of these gases from a homogeneous source rock into a system which contains both pore liquid and gas would, in the absence of complete diffusive equilibrium, tend to make $C_{i}{ }^{0}<K_{i} C_{i}$. Under such conditions, the concentration of species $i$ in the gas phase would be lower than expected by diffusive equilibrium. Except for minor effects brought about by the temperature dependency of the Henry's law constant, it is difficult to envision a natural situation which would tend to make $C_{i}{ }^{\circ}>K_{i} C_{i} \cdot$. With reference to radiogenic helium, only if a source material is selectively contributing the helium to a gas phase at a rate of $K_{\mathrm{H}}$ times faster than it is feeding a liquid phase can $C_{\mathrm{H}_{0}{ }^{\circ}}$ be greater than $K_{\mathrm{He}_{0}} C_{\mathrm{H}_{0}}$.

Radon. The existence of radon in many natural gases has sometimes been used to infer 
the presence of a concentration of uranium in the neighborhood of such occurrences. Faul, Gott, Manger, Mytton, and Sakakura [1954] have reported on the Rn content of some helium-rich natural gases. These workers conclude that it is uncertain whether the high helium content of certain gases is related to the presence of $\mathrm{Rn}$. This problem is of interest in considering the possibility that a significant portion of the $\mathrm{He}$ in some natural gases can be the product of $U$, Th decay in their present reservoir.

Sakakura, Lindberg, and Faul [1959] have reported the radon content in the gases from four wells as a function of the cumulative production, starting from a situation where the wells had been shut down for 2 or 3 weeks. The net gas flow required before the $\mathrm{Rn}$ concentration reached a constant value was small and of such a value as to indicate that the principal source of the activity was not in the well hole itself but immediately adjacent. These workers have presented a theoretical treatment of the problem of the gas transport of Rn. They conclude that for the Texas Panhandle gases the $R n$ is due to a uranium concentration of between 0.4 and $9.0 \mathrm{ppm}$, assuming an emanating power of 10 per cent.

In the following, we will present a simplified treatment of the steady state transport problem that will suffice for the purpose at hand.

The equation governing the steady state concentration of $\mathrm{Rn}$ in a fluid phase for the case of cylindrical symmetry is given by

$$
\frac{1}{r} \frac{d[r \cdot C(r) \cdot J(r)]}{d r}=-\lambda p C(r)+p q(r)
$$

Here $C(r)$ is the concentration of $\mathrm{Rn}$ in the fluid phase at distance $r, J(r)$ is the outward radial volume flux of fluid with the dimensions of velocity, $p$ is the porosity, $q(r)$ is the rate of generation of $\mathrm{Rn}$ per cc of pore space, and $\lambda$ is the decay constant for Rn. If the fluid is incompressible, $J(r)=Q / 2 \pi H r$, with $-Q / H$ being the volume of fluid yielded by the well per unit height of the producing horizon.

If the production rate of $\mathrm{Rn}$ is everywhere constant, we see that $C=q / \lambda$. The Rn activity is then constant and equal to the production rate. If the fluid is compressible, the concentration is a more complicated function of position due to the fact that at lower pressures the fluid occupies a greater volume. For simplicity, we will consider gases as incompressible, and take the rate of production $Q$ in units of cc volume at well pressure per unit time.

For the case of the uniform production of $R \mathbf{n}$ within a cylinder of radius $R$ center about the origin and no production outside of this region, the value of $C$ at the well is

$$
C(0)=q / \lambda\left[1-\exp \frac{\lambda \pi H p R^{2}}{Q}\right]
$$

It is clear that $C(0)$ is insensitive to changes in the parameters at distances much greater than $r=(-Q / \lambda \pi H p)^{t}$, i.e., distances for which the time of travel to the well is equal to the mean life. This distance is probably not in excess of a few hundred feet for most wells.

The highest Rn concentration in the Panhandle helium wells reported by Faul, Gott, Manger, Mytton, and Sakakura [1954] is 500 micromicrocuries per liter at STP. Using a well head pressure of 16 atmospheres we obtain for a uniform source $q=\lambda C \simeq 0.24 \mathrm{Rn}$ decay/sec. ce of pore space. Assuming a porosity of 10 per cent, this corresponds to an emanating uranium concentration of $10^{-1} \mathrm{~g} \mathrm{U} / \mathrm{g}$ rock. If but 1 per cent of the emanation escapes to the pores, this corresponds to a uranium concentration of only $100 \mathrm{ppm}$. For a well in the San Juan basin containing 6 per cent He, Faul, Gott, Manger, Mytton, and Sakakura [1954] report a Rn activity of only 5 micromicrocuries/liters STP.

In some of the cases reported, the $R n$ level was sufficient to account for the helium present, assuming steady production for $10^{\mathrm{s}}$ years. In others, it could contribute only 0.1 per cent of the He. Since more He may escape from the reservoir rocks than is indicated by the $R n$ concentration, it is quite possible that some gases obtain their helium after their final entrapment. In any case, the $\mathrm{Rn}$ data do not support the case for the generation of these helium containing gases from high uranium concentrations.

Helium distribution function. There are about 3400 helium analyses for natural gases as reported by the U.S. Bureau of Mines [Anderson and Hinson, 1951; Boone, 1958]. The gases analyzed come from a wide variety of geological situations and, excluding the very high helium wells, should be a representative sample of natural gas accumulations. Because of the large number of analyses, it should be possible to get a rather 


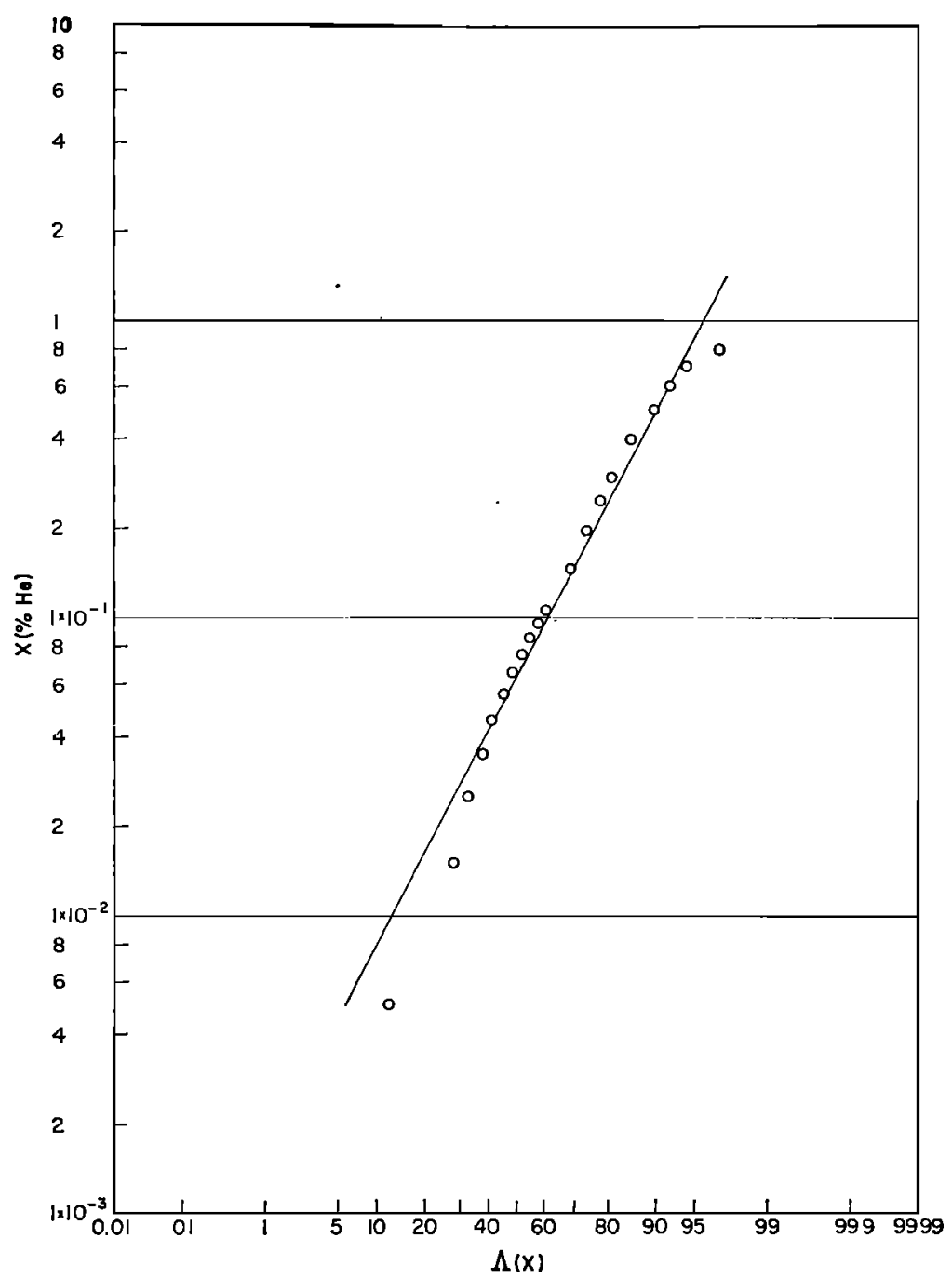

Fig. 3. Log probability plot of the helium abundance in natural gases. Statistics for abundances less than 0.8 per cent and estimates for high helium production are taken from U. S. Bureau of Mines data.

good description of their frequency curve. The data used were 3000 analyses of samples containing less than 0.8 per cent He. Because an excessive number of samples were analyzed from known He-producing areas, we have discarded all analyses reporting over 0.8 per cent He. Using estimates of the total annual gas production and their helium content, we obtained the result that 3 per cent of the total gases contained helium in a concentration of over 0.8 per cent. This fraction of the annual gas production las an average He concentration of 1.5 per cent [U.S. Bureau of Mines, 1959].

Using these data, a frequency histogram was constructed. The cumulative data, plotted on log probability paper, are shown in Figure 3. It is evident that a lognormal distribution represents the data fairly well. The percentiles were determined [Aitchison and Brown, 1957]. using the straight line drawn through the points. The following values were determined for this curve: 


$$
\begin{array}{rlrl}
\text { mean } & =0.2170 \% & & \\
\text { median } & =0.0610 \% & \sigma & =1.59 \\
\text { mode } & =0.0049 \% & \mu=2.80
\end{array}
$$

Figure 4 illustrates the frequency curve and uses these parameters for the frequency function

$\frac{d \Lambda(x)}{d x}=\frac{1}{2 \pi \sigma x} \exp -\left\{\frac{(\ln x-\mu)}{\sqrt{2 \sigma}}\right\}^{2}$

This curve may be compared with the histogram.

The histogram does not appear to have bimodal characteristics. This observation further suggests that the high $\mathrm{He}$ gases do not (in a statistical sense) represent any special mechanism, but rather represent low-probability events on the tail of a continuous-probability curve.

\section{SAMPLES}

Samples 1-7 are gases from Eocene and Cretaceous sands of the Sacramento Valley, California. They have a wide range in $(\mathrm{He} / \mathrm{A})_{\mathrm{rad}}$ and $\left(\mathrm{N}_{2} / \mathrm{A}_{\text {nir }}\right)$ ratios, and their $\epsilon$ is rather low. The radiogenic helium and argon content of these gases is among the lowest observed in any analyzed samples. The atmospheric argon content of these gases ranges between 44 and $124 \mathrm{ppm}$; the nitrogen varies from less than 1 per cent to over 30 per cent. Geologic evidence indicates that the reservoir rocks may be in communication with ground water circulation. These Tertiary and Cretaceous sediments crop out a short distance to the east along the western foothills of the Sierra Nevada. The young age of the sediments may account for the low radiogenic noble gas content of these natural gases, and the possibility of open system conditions or heterogeneity in the source material is suggested by the large variations in the $(\mathrm{He} / \mathrm{A})_{\mathrm{rad}}$ and $\left(\mathrm{N}_{2} / \mathrm{A}_{\text {air }}\right)$ ratios. Chemically, the Sacramento Valley gases are extremely dry, with methane making up essentially all the hydrocarbon fraction and nitrogen varying between 1 and 30 per cent. That all this nitrogen cannot be of direct atmospheric origin has been discussed previously. Sample 6 from the Marysville-Butte field was taken from gas closely associated with Pleistocene volcanic extrusives.

Samples 8-10 and 36-39 are gases occurring

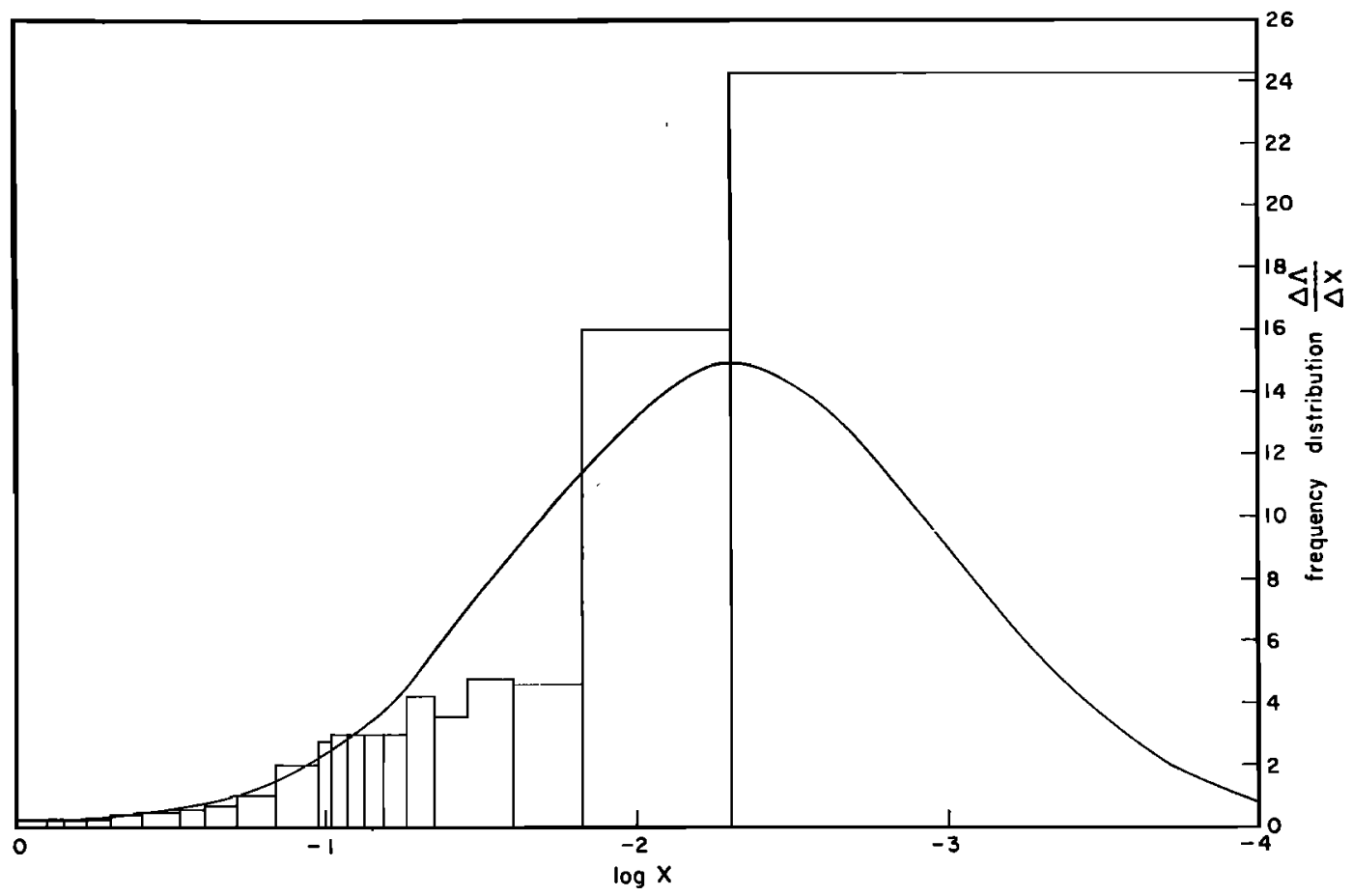

Fig. 4. Frequency curve and histogram showing the distribution of helium in natural gases. 
in rocks of Cretaceous to Eocene age from northwestern Colorado and southwestern Wyoming. Although these gases also show wide variations in $\left(\mathrm{N}_{2} / \mathrm{A}_{\text {air }}\right)$ and $\epsilon$, their $(\mathrm{He} / \mathrm{A})_{\mathrm{rad}}$ ratio remains fairly constant despite over an order of magnitude variation in radiogenic helium and argon content. Whereas the chief factor producing the spread observed in the $\left(\mathrm{N}_{2} / \mathrm{A}_{\text {air }}\right)$ ratio for the Sacramento Valley gases was a highly variable nitrogen content, the Green River gases, which demonstrate an even greater range in $\left(\mathrm{N}_{2} / \mathrm{A}_{\mathrm{sir}}\right)$ ratios, have more uniform nitrogen content, but over an order of magnitude variation in air argon content. Thus, these gases may represent either (1) reservoirs of highly variable $V \cdot V^{\circ}$, (2) reservoirs into which air argon from sources other than saturated sea water was introduced, (3) reservoirs in which varying degrees of diffusive disequilibrium exist, or (4) samples having incorporated air argon owing to varying levels of contamination.

Samples 12 and 13 were selected to represent gases from a present-day geosynclinal environment.

Samples 18-20 are from Lea County, New Mexico. The first two gases are produced from Permian sandstones. Sample 18 comes from a reservoir directly overlying the reservoir of sample 19 and is stratigraphically separated from it by about 1000 feet of section. The other gas occurs in a Permian carbonate. The similarity in the $(\mathrm{He} / \mathrm{A})_{\mathrm{rad}}$ ratio, the $\left(\mathrm{N}_{2} / \mathrm{A}_{\mathrm{air}}\right)$ ratio, and $\epsilon$ for these samples from the sandstone reservoirs may be a reflection of a similar source. The gas from the limestone reservoir appears to be distinctly different in these parameters from the other two gases.

Sample 23 from western New York and samples 25-27 from Pennsylvania represent Paleozoic gases from the Appalachian petroleum province. These gases contain the highest $(\mathrm{He} / \mathrm{A})_{\mathrm{rad}}$ ratios found in any of the samples; they range from 26.2 to 134 . Such a high ratio is quite surprising in these gases because of their relatively great age, low $V \bullet / V q$, and proximity to orogenic activity, which may have been more effective than average in releasing radiogenic argon. All of these features point toward a low $(\mathrm{He} / \mathrm{A})_{\mathrm{rad}}$ ratio.

On the other hand, it is possible that some distillation mechanism has been particularly operative in the production of these gases and has selectively enriched the gas phase in helium. The low value of $V \% V^{\circ}$ may in reality point to the removal or absence of air argon from the system. If the high value of $R$ did result from a distillation mechanism operating on an originally normal $(\mathrm{He} / \mathrm{A})_{\text {rad }}$ ratio, there should exist somewhere a complimentary phase having a correspondingly low value of $R$. It is also possible that the sources of the western Appalachian gases are characterized by a low $\mathrm{K} / \mathrm{U}$ ratio. Whereas such a ratio might be expected to occur in impure limestones, the fact that most of the Appalachian gases occur in stratigraphic traps, involving sandstone lenses surrounded by impervious shales, seems to exclude this possibility. In no way does this region demonstrate a $(\mathrm{He} / \mathrm{A})_{\text {rad }}$ ratio to be expected by a simple degassing of a chondritic mantle.

Samples 11 from the Sexson field, Kansas, 22 from a wildcat well in San Juan County, New Mexico, 24 from the Keyes field in Oklahoma, and 29-32 from the West Panhandle field, Texas, were selected as representative high helium natural gases. They range between 0.5 and over 6 per cent helium with $(\mathrm{He} / \mathrm{A})_{\text {rad }}$ ratios ranging from 11.1 to 23.3. Such values of $R$ are in no way compatible with a large increase in the concentration of uranium and thorium over potassium as compared with average rocks. As stated elsewhere, it is the authors' opinion that high helium wells result from the favorable interaction of several processes operating on normal rock types having average $U$, Th, and $\mathrm{K}$ contents. Some of these high helium reservoirs, such as those of the Texas Panhandle field, appear to be closely related to buried Precambrian granite and granite wash, which may have been the source of the helium [Cotner and Crum, 1935]. In other areas, such as San Juan County, New Mexico, no such correlation with basement rock is obvious [Hinson, 1947]. In many cases, however, the high helium reservoirs are stratigraphically low in areas containing several reservoir horizons. This would be expected if helium, having been liberated from the basement, rose through the overlying sediments until it became incorporated into the first reservoir it encountered. Numerous exceptions to the occurrence of high helium gases in low stratigraphic horizons exist. Rogers [1921] found that in the mid-continent region it may be that certain intermediate horizons, or even the highest 
producing zone, contain the largest percentage of helium. It is still not possible to give a rigid explanation of the processes by which certain reservoirs became highly enriched in helium.

These gases contain between 50 and 200 ppm of atmospheric argon. A comparison between the $\mathrm{A}^{40} / \mathrm{A}^{\text {so }}$ ratio as given by Wasserburg, Czamanske, Faul, and Hayden [1957] and by this paper (sample 31, Table 2) shows a much greater enrichment in radiogenic argon for our analysis. This is most likely due to atmospheric contamination in the older analysis. All of the Texas Panhandle gases now have similar $\mathrm{A}^{10} / \mathrm{A}^{30}$ ratios, and this is believed to be a regional characteristic. All of the high helium gases have $\left(\mathrm{N}_{2} / \mathrm{A}_{\text {air }}\right)$ ratios of an order of magnitude or more higher than the atmospheric value.

Sample 22 was observed to have a minimum possible value of $\left(\mathrm{A}^{40} / \mathrm{A}^{38}\right)_{\mathrm{rad}}$ of $1.9 \times 10^{5}$. This value is larger than the maximum value predicted by Gerling, Levskii, and Afanasyeva [1956] by a factor of 2.4 and, therefore, adds additional evidence [Wasserburg and Bieri, 1958; Signer and Nier, 1959] against the presence of a long-lived isomer of $\mathbf{K}^{\text {si. }}$.

Samples 16, 17, 34, and 35 were chosen to include carbon dioxide gases in the survey. The Bueyeros field gases, which are over 99.8 per cent $\mathrm{CO}_{2}$, show the lowest $(\mathrm{He} / \mathrm{A})_{\text {rad }}$ ratios of any gas analyzed. They also contain less than $0.5 \mathrm{ppm}$ atmospheric argon, and have $\epsilon$ 's of $0.98-0.99$. The Farnham Dome gases contain approximately 99.3 per cent $\mathrm{CO}_{2}$. They also have quite low $(\mathrm{He} / \mathrm{A})_{\mathrm{rad}}$ ratios and high values of $\epsilon$. Both these gas fields occur in areas containing carbonate rock and Tertiary basaltic intrusives and lavas. Geologic evidence, as well as carbon isotopic data which will be discussed later in this report, suggests that the $\mathrm{CO}_{2}$ was derived from the decomposition of carbonate rocks during metamorphism by the basalt. Under such conditions, it is possible that most of the original gases and liquids in the near-by sediments were driven off before the carbon dioxide accumulation. This would explain the high purity of the $\mathrm{CO}_{2}$ and the extremely low atmospheric argon content of the gases. Since the molten basalt might cause a relatively higher release of radiogenic argon, compared to radiogenic helium, than results from low temperature diffusion, we could expect such an environment to yield low values of $(\mathrm{He} / \mathrm{A})_{\mathrm{rad}}$.
Sample 40 from Texas and sample 41 from Alberta, Canada, were included to represent gases from carbonate reef environments. They show no indication of an abnormally high $(\mathrm{He} / \mathrm{A})_{\mathrm{rad}}$ ratio as might be expected from pure carbonate sources. Sample 41 contains 12.2 per cent $\mathrm{H}_{2} \mathrm{~S}$.

\section{Carbon Isotopes}

Isotopic analyses were made on some of the carbon compounds contained in the gases. The results are shown in Table 3 . The isotopic composition of the carbon is given in terms of its delta $(\delta)$ value relative to the Chicago standard, PDB [Craig, 1953].

Most of the California samples were run only as total gas; however, since they generally contained less than 0.1 per cent $\mathrm{CO}_{2}$, and very little ethane, propane, ete., the total gas carbon is very nearly equal to the methane carbon. Several of the Texas Panhandle and the Keyes, Oklahoma, high helium gases were also run only as total gas. A comparison with samples 29 and 30 from the Texas Panhandle area, in which both total carbon and methane carbon were run, indicates that about a 1-2 per mil difference may be expected between total gas and methane carbon for this suite, with the methane having the lighter carbon. The remainder of the natural gases were analyzed for methane carbon, and in some cases an additional analysis of total gas carbon was made. The carbon dioxide well gases were analyzed for $\mathrm{CO}_{2}$ carbon only. Carbon dioxide was analyzed from all natural gas samples containing more than 0.2 per cent $\mathrm{CO}_{2}$ with the exception of sample 24. All of the methane analyses give delta values between $-57.6^{*}$ and -29.2 per mil. Both these extreme values are from wells within the Sacramento Valley gas fields of California. Usually individual gasproducing districts possess a much narrower range in methane carbon composition. This is exemplified by samples 8-10 and 36-39 from the Green River area and samples 29-33 from the Texas Panhandle. The methane carbon from the Green River suite lies between -38.5 and

* Although this analysis for sample 5 refers to total gas carbon, it is from a gas essentially free of $\mathrm{CO}_{2}$ and other hydrocarbons; therefore, it undoubtedly is within a few tenths of a per mil of the methane value. 
-43.5 per mil, and the total carbon from the Texas Panhandle gases suggests an even narrower range.

These results are similar to the observations made by Silverman and Epstein [1958] and Wasserburg, Czamanske, Faul, and Hayden [1957], who found that methane has the lightest carbon found in nature. The exact mechanism by which methane is produced is not known at present. It is probable that some breakdown of organic matter, either by bacterial or inorganic processes, results in the liberation of methane. It was noted by Silverman and Epstein [1958] that natural gas carbon is generally lighter than associated petroleum, and that this in turn is lighter than the organisms from which it is supposedly derived. Rosenfeld and Silverman [1959] have found an unusually high fractionation between methanol and the methane which is produced from it by anserobic bacterial decomposition. The methane is about 8 per cent enriched in $\mathrm{C}^{12}$ relative to the methanol. Further investigation of the origin of methane is required before a more specific discussion of its $\mathrm{C}^{18} / \mathrm{C}^{13}$ ratio can be made.

An analysis was made of a sample of gas collected by Louis Gordon from a gas-seep over the head of the north fork of Scripp's Canyon off the coast of southern California near La Jolla. The delta value for this sample was -44.2; it falls in the same general range as the well methanes. K. O. Emery (personal communication) considers this gas to be a seep from a subsurface source.

In those gases where total methane and $\mathrm{CO}_{2}$ carbon were analyzed, it was possible to calculate approximate ranges of the $\delta$ value for the higher hydrocarbons. Because small uncertainties in the known $\delta$ values are greatly increased in such a calculation, it can only be concluded that the $\delta$ value of the higher hydrocarbons is generally 5-15 per mil greater than the methane.

If we consider the carbon dioxide gases, we see that they are often associated with stratigraphic sections also containing carbonate rock and igneous intrusives and lavas. Lang [1959] found that the $\mathrm{C}^{12} / \mathrm{C}^{12}$ ratios of several $\mathrm{CO}_{2}$ gases lay within the range of carbon in marine limestones. This is in agreement with the theory that the $\mathrm{CO}_{2}$ comes from the nonequilibrium dissociation of carbonate during contact metamorphism. The results from the two $\mathrm{CO}_{2}$ fields studied in this report are in agreement with the work of Lang.

The isotopic composition of the oxygen from three of the carbon dioxide wells was also determined. Mitchell No. 4, Farnham Dome No. 2, and Farnham Dome Equity gave values of $\delta_{\mathrm{CO}}$, relative to PDB of $-23.0,-20.2$, and -20.3 per mil respectively. Such values might be expected either for $\mathrm{CO}_{2}$ produced by the high temperature decomposition of marine carbonate or possibly by $\mathrm{CO}_{2}$ in equilibrium with certain reservoir waters at appropriate temperatures. In the first case, if fractionation of only a few per mil occurred between the carbonate and $\mathrm{CO}_{2}$ during such high temperature processes as contact metamorphism, we would obtain values of $\delta_{\mathrm{CO} 2}$ close to those of marine carbonate, i.e., -20 to -10 per cent [Clayton and Epstein, 1958; Engel, Clayton, and Epstein, 1958] recomputed relative to the acid extracted PDB standard. In the second case, we see that although the $\delta$ value is too low to represent $\mathrm{CO}_{2}$ in equilibrium with normal marine water at room temperatures such values might result from equilibration with light waters or at elevated temperatures. [Epstein and Mayeda, 1953].

At least traces of carbon dioxide are observed in nearly all natural gases, and gases ranging in composition up to almost pure $\mathrm{CO}_{2}$ have been found. Some literature [Lang, 1959; Miller, 1937] has been published on the origin of high carbon dioxide gases; however, no detailed work has been done on the $\mathrm{CO}_{2}$ in ordinary petroleum gases. Here, the $\mathrm{CO}_{2}$ generally makes up between a few hundredths of a per cent and a few per cent of the total gas.

The $\delta$ values for all the $\mathrm{CO}_{2}$ analyses are seen to lie between -21.9 and +12.8 . In every case, the $\mathrm{CO}_{2}$ carbon is considerably heavier than that of the coexisting methane or total gas. This is a remarkable regularity which must have important genetic significance.

If we assume that the $\mathrm{CH}_{4}-\mathrm{CO}_{2}$ pairs were in isotopic equilibrium within a gas phase under certain conditions, and that subsequent to that time these values were 'quenched in,' we may calculate effective temperatures. Such temperatures were computed using the fractionation factor as calculated by Craig [1953]. These results are given in Table 3. Since the kinetics 
of this exchange are completely unknown, we are unable to say under what conditions we would expect equilibrium to occur and be frozen in. The possible ranges in temperature which we might obtain, assuming equilibrium to have occurred at some time, are room temperature and the maximum temperature which these gases may have experienced. Some of the calculated temperatures range up to several hundred degrees centigrade. This is considerably in excess of the actual well temperatures. Since it is generally agreed that petroleums do not result through high temperature processes of formation, we conclude that some of these gases lie well outside the range to be expected from equilibrium considerations.

Although it is thus doubtful that complete isotopic equilibrium prevails, it is impossible to say whether the $\mathrm{CH}_{4}-\mathrm{CO}_{2}$ pairs represent a partial attainment of isotopic equilibrium. It is significant that in every case of unreasonable temperature, the $\delta_{\mathrm{co}}$, value appears to be lower than the expected equilibrium value. That is, if isotopic equilibrium were to be attained in those gases, $\delta_{\mathrm{CO}}$, would have to become more positive. Thus, assuming only equilibrium processes to be operative between the $\mathrm{CO}_{2}$ and the $\mathrm{CH}_{4}$, the observed $\delta$ values would represent the maximum value which they could have originally had. Although nine of the samples listed in Table 3 have values of $\delta_{\mathrm{co}}$, greater than -10 per mil and, therefore, may have possibly arisen by either the equilibrium or disequilibrium breakdown of marine carbonate rock, the other seven samples for which we have data give $\delta$ values too negative to represent such a source. If we assume that all the carbon dioxides once had $\delta$ values at least as negative as the lightest sample now observed $(\sim-20$ per mil) and that the present spread resulted from later partial equilibration, we must look for other sources of carbon capable of yielding such values.

When $\mathrm{CO}_{2}$ occurs in much smaller concentrations than $\mathrm{CH}_{4}$, any change toward equilibrium in the isotopic composition of the system would cause a much greater change in the $\mathrm{C}^{13} / \mathrm{C}^{12}$ ratio of the $\mathrm{CO}_{2}$ than of the $\mathrm{CH}_{4}$. Thus, while such a process will affect the original $\delta_{\mathrm{CH}_{\star}}$ value only weakly, even partial attainment of equilibrium will tend to obscure any original value of $\delta_{\mathrm{Co}_{2}}$.

At present, it is not possible to explain uniquely the genesis of the carbon dioxide found in petroleums.

\section{Conclusions}

All the natural gases studied exhibit values of $R$ which indicate that they are of a common family and have obtained their radiogenic gases from rather average rock types. The variations in abundance of radiogenic helium and argon in these gases are due to the effects of leakage and entrapment, solubility, porosity, and age of the source rocks. Major differences in the abundances of $\mathrm{He}$ cannot be due to large variations (over a factor of 50 ) in the abundance of $U$ and $\mathrm{Th}$ in the source rocks.

For many cases studied, only a small fraction of the $\mathrm{N}_{2}$ present may be attributed to the incorporation of air.

The methane was found to have extremely light carbon as suggested by previous workers. In addition, it was found that the carbon isotopic composition of $\mathrm{CO}_{2}$ was always heavier than in the coexisting $\mathrm{CH}_{4}$. This could not be reasonably attributed to complete isotopic equilibrium between these gaseous species.

It is possible that the concentration of atmospheric argon in a gas reservoir may be correlatable with the amount of reservoir water with which it was equilibrated.

Acknowledgments. This work could not have been carried out without the generous assistance of the many people who aided us in obtaining samples. In particular, we would like to thank the members of the following organizations which supplied us with material: The U. S. Bureau of Mines Helium Activity Station, The Mountain Fuel Supply Co., Skelly Oil Company, Carbonic Chemicals Corporation, Carbon Dioxide and Chemical Company, Humble Oil and Refining Company, United Natural Gas Company, Iroquois Gas Corporation, The Sylvania Corporation, Standard of California and affiliates, and The Ohio Oil Company and affiliates, and Continental Oil Company and affiliates.

We would like to thank Dr. S. Epstein for granting us the liberal use of his laboratory and for his continued interest in this problem. We also wish to thank Dr. Sol Silverman and Dr. K. Chave who contributed several valuable suggestions. Mr. C. W. Mink assisted in the mass spectrometric work at Berkeley.

Contribution No. 978 of the California Institute of Technology was supported by a National Science Foundation Grant, and in part by a grant in aid from the California Research Corporation and by a grant from the Atomic Energy Commission. 


\section{REFRRENCES}

Adams, J. A. S., J. E. Richardson, and C. C. Templeton, Determination of thorium and uranium in sedimentary rocks by two independent methods, Geochim. et Cosmochim. Acta, 1s, 270-279, 1958.

Akerlof, Gösta, The solubilities of noble gases in aqueous salt solutions at $25^{\circ} \mathrm{C}, J$. Am. Chem. Soc., 57, 1196-1201, 1935.

Aldrich, L. T., and A. O. Nier, The occurrence of hellium-3 in natural sources of helium, Phys. Rev., 74, 1590-1594, 1948.

Aitchison and Brown, The Lognormal Distribution, University Press, Cambridge, 176 pp., 1957.

Anderson, C. C., and H. H. Hinson, Helium-bearing natural gases of the United States, Bureau Mines Bull., 486, 141 pp., 1951.

Baranov, V. L., A. B. Ronov, and K. G. Kunashova, Geochemistry of thorium and uranium in clays and carbonate rocks of the Russian platform, Geokhim., Izd. Akad. Nauk SSSR, 8, 3-8, 1956.

Bate, G. L., J. R. Huizenga and H. A. Potratz, Thorium in stoue meteorites by neutron activation analysis, Geochim. et Cosmochim. Acta, 16, 88-100, 1959.

Bell, K. G., Uranium in precipitates and evaporites, U. S. Geol. Survey Profess. Paper 300, 381-386, 1956.

Boone, W. J., Jr., Helium-bearing natural gases of the United States, Bur. Mines Bull., 576, 117 pp., 1958.

Cady, H. P., and D. F. McFarland, Helium in Kansas natural gas, Science, 24, 344, 1906.

Clayton, R. N. and S. Epstein, The relationship between $\mathrm{O}^{18} / \mathrm{O}^{10}$ ratios in coexisting quartz, carbonate, and iron oxides from various geological deposits, J. Geol., 66, 352-373, 1958.

Cotner, Victor, and Crum, H. E., Geology and occurrence of natural gas in Amarillo district, Texas, Geology of Natural Gas, Am. Assoc. Petrol. Geol., 385-415, 1935.

Craig, Harmon, The geochemistry of the stable carbon isotopes, Geochim. et Cosmochim. Acta, 3, 53-92, 1953.

Dumon, P. E., and J. L. Kulp, Excess helium and argon in beryl and other minerals, $A m$. Mineral., $48,433-459,1958$.

Eklund, Josef, Urantillgångar och Energiförsörjning, Kosmos (Swed.) 24, 74, 1946.

Engel, A. E. J., R. N. Clayton, and S. Epstein, Variations in isotopic composition of oxygen and carbon in Leadville limestone (Mississippian, Colorado) and in its hydrothermal and metamorphic phases, J. Geol., 66, 374-393, 1958.

Epstein, S., and T. Mayeda, Variation of $\mathrm{O}^{18}$ content of waters from natural sources, Geochim. el Cosmochim. Acta, 4, 213-224, 1953.

Evans, R. D., and C. Goodman, Radioactivity of rocks, Bull. Geol. Soc. Am., 52, 459-490, 1941.

Faul, Henry, G. B. Gott, G. E. Manger, J. W. Mytton and A. Y. Sakakura, Radon and helium

- in natural gas, Compt. rend. 19 e Congr. Geol. Intern. Alger. Sec. 9, 339-348, 1954.

Geiss, Johannes, and D. C. Hess, Argon-potassium ages and the isotopic composition of argon from meteorites, Astrophys. J., 127, 224-236, 1958.

Gerling, E. K., L. K. Levskii, and L. I. Afanasyeva, On the discovery of $\mathrm{A}^{\text {as }}$ in potassium-containing minerals, Dokl. Akad. Nauk SSSR 109, 813-815, 1956.

Goldich, S. S., H. Baadsgaard, A. O. Nier, and J. H. Hoffman, The reproducibility of $A^{40} / K^{40}$ age determinations, Trans. Am. Geophys. Union, 38, 547-551, 1957.

Goryunov, M. S. and A. L. Kozlov, Voprosy geolchumii gelienosnylch gazov $i$ usloviia nakopleniia $v$ semnoi kore., Russian (State Sci.-Tech. Pub. Co. Oil and Solid Fuel Lit.), Leningrad-Moscow, 1940.

Hamaguehi, H., G. W. Reed, and A. Turkevich, Uranium and barium in stone meteorites, Geochim. et Cosmochim. Acta, 12, 337-347, 1957.

Hill, R. D., Production of helium-3, Phys. Rev., 59, 103, 1941.

Hinson, H. H., Reservoir characteristics of Rattleanake oil and gas field, San Juan County, New Mexico, Bull. Am. Assoc. Petrol. Geol., 31, 731-771, 1947.

Hoering, T. C., Nat. Acad. Sci., Nat. Res. Council Pub., 57\&, Nuclear Science Series Report No. 23, 161-170, 1957.

Hurley, P. M., and C. Goodman, Helium retention in common rock minerals, Bull. Geol. Soc. Am., $52,545-560,1941$.

Joly, J., The amount of thorium in sedimentary rocks, II, Arenaceous and argillaceous rocks, Phil. Mag., 20, 353, 1910.

Keevil, N. B., Helium retentivities of minerals, $A m$. Minerol., $26,403-404,1941$.

Lang, W. B., The origin of some natural carbon dioxide gases, $J$. Geophys. Research, 64, 127-131, 1959.

McCrea, J. M., Ph.D. Thesis, University of Chicago, 1949: On the isotopic chemistry of carbonates and a paleotemperature scale, J. Chem. Phys., 18, 849-857, 1950.

McKinney, C. R., J. M. McCrea, S. Epstein, H. A. Allen, and $H$. C. Urey, "Improvements in mass spectrometers for the measurement of small differences in isotope abundance ratios," Rev. Sci. Instr., 21, 1950, p. 724-730.

Miller, J. C., Carbon dioxide accumulations in geologic structures, Am. Inst. Mining Met. Engrs. Tech. Pub., 841, 28 pp., 1937.

Morrison, P., and J. Pine, Radiogenic origin of the helium isotopes in rock, Ann. New York Acad. Sci., 62, 69-92, 1955.

Murray, E. G., and J. A. S. Adams, Thorium, uranium and potassium in some sandstones, Geochim. et Cosmochim. Acta, 19, 260-269, 1958.

Nier, A. O., A redetermination of the relative abundances of the isotopes of carbon, nitrogen, oxygen, argon, and potassium, Phys. Rev., 77, 789-793, 1950.

Nockolds, S. R., Chemical compositions of some igneous rocks, Bull. Geol. Soc. Am., 65, 1007$1032,1954$. 
Norton, F. J., Helium diffusion through glass, $J$. Am. Cer. Soc., \$6, 90-96, 1953.

Palache, C., H. Berman, and C. Frondel, The System of Mineralogy, Vol. I, John Wiley and Sons, Inc., New York, 834 pp., 1944.

Palache, C., H. Berman, and C. Frondel, The System of Mineralogy, Vol. II, John Wiley and Sons, Inc., New York, 1124 pp., 1951.

Rakestraw, N. W., and V. M. Emmel, The solubility of nitrogen and argon in sea water, $J$. Phys. Chem., 48, 1211-1215, 1938.

Rankama, Kalervo, and T. G. Sahama, Geochemistry, University of Chicago Press, Chicago, 912 pp., 1950.

Rayleigh, Lord, Nitrogen, argon and neon in the earth's crust with applications to cosmology, Proc. Roy. Soc., London, 170, p. 451, 1939.

Rogers, G. S., Helium-bearing natural gas, $U$. $S$. Geol. Survey Profess. Paper, 121, 113 pp., 1921.

Rosenfeld, W. D., and S. R. Silverman, Carbon isotope fractionation in bacterial production of methane, Science, 130, 1658-1659, 1959.

Sakakura, A. Y., Carolyn Lindberg, and Henry Faul, Equation of continuity in geology with applications to the transport of radioactive gas, U. S. G. S. Bull., 105\&-I, 287-305, 1959.

Satterly, J., and J. C. McLennan, The radioactivity of the natural gases of Canada, Trans. Roy. Soc. Canada, sec. III, 12, 153-160, 1918.

Senftle, F. E., and N. B. Keevil, Thorium-uranium ratios in the theory of genesis of lead ores, Trans. Am. Geophys. Union, 28, 732-738, 1947.

Signer, P., and A. O. Nier, An upper limit for radiogenic $\mathrm{A}^{38}$ in potassium minerals, Geochim. et Cosmochim. Acta, 16, 302-303, 1959.

Silverman, S. R., and S. Epstein, Carbon isotopic composition of petroleums and other sedimentary organic materials, Bull. Am. Assoc. Petrol. Geol., 4R, 998-1012, 1958.

Tatsumoto and Goldberg, Geochim et Cosmochim. Acta, 1\%, 201-208, 1959.

Tomkeieff, S. L., The geochemistry of uranium, Science Progress, 34, 696, 1946.

U. S. Bureau of Mines, Minerals Yearbook, 1958, Vol. II, Fuels, U. S. Government Printing Office, Washington, 484 pp. 1959.

Urey, H. C., H. Lowenstam, S. Epstein, and C. R. McKinney, Measurements of paleotemperatures, Geol. Soc. Am. Bull., 62, 399-416, 1951.

Wasserburg, G. J., G. Czamanske, H. Faul, and R. J. Bayden, Nat. Acad. Sci., Nat. Res. Council Pub. 57\&, Nuclear Science Series Report No. 23, $156-158,1957$.

Wasserburg, G. J., and R. Bieri, The $A^{38}$ content of two potassium minerals, Geochim. et Cosmochim. Acta, 15, 157-159, 1958.

Wasserburg, G. J., and R. J. Hayden, $A^{40-K} K^{40}$ dating, Geochim. et Cosmichim. Acta, 7, 51-60, 1955.

Wasserburg, G. J., R. J. Hayden, and K. J. Jensen, $\mathrm{A}^{40}-\mathrm{K}^{40}$ dating of igneous rocks and sediments, Geochim. et Cosmochim. Acta, 10, 153-165, 1956.

Wetherill, G. W., Variations in the isotopic abun- dances of neon and argon extracted from radioactive minerals, Phys. Rev., 96, 679-683, 1954.

Wetherill, G. W., Spontaneous fission yields from uranium and thorium, Phys. Rev., 98, 907-912, 1953.

Zobell, C. E., Part played by bacteria in petroleum formation, J. Sed. Pelr., $22,42-49,1952$.

\section{Arpindix}

Potassium and uranium in carbonates. Of the common rocks, limestones may exhibit wide variations in the content of trace elements such as potassium and uranium. For this reason, various carbonates of known uranium content were analyzed for potassium. The measurements were made with a Perkin-Elmer flame photometer. Samples of the carbonates weighing 1.02 gram were dissolved in $\mathrm{HCl}$ and evaporated to dryness. They were put into aqueous solution with $1 \mathrm{ml}$ of $12 \mathrm{~N} \mathrm{HCl}$ and diluted to $250 \mathrm{ml}$ volume. The solutions were run on the flame photometer and the readings compared with those obtained on identically prepared $\mathrm{CaCO}_{3}$ solutions of known potassium content. The results were highly reproducible, and at concentrations above $100 \mathrm{ppm}$ the data are probably accurate to within 10 per cent of the values reported. The data are given in Table 6. Column 2 of this table gives the per cent of the $\mathrm{CaCO}_{3}$ that is aragonite.

Samples of the Bikini atoll cores had been analyzed previously for uranium by Dr. M. S. Coops of the Radiation Laboratory, Livermore, California. The analyses were done using a neutron activation technique in which the $\mathrm{Np}^{239}$ was counted. Dr. Coops kindly provided us with these samples.

Some of the uranium analyses are the results reported by Tatsumoto and Goldberg [1959] using a colorimetric method. Dr. Goldberg generously provided us with some of these samples, and in addition made other uranium analyses reported here. Two samples of marbles analyzed for uranium by Dr. B. Doe are also included.

The analytical method used in each case is given in the table.

It is evident that in the carbonate rocks reported here the potassium content is widely variable. The Muschel Kalk had the highest value of 4,600 ppm and the Algal ls. and Leadville ls. the lowest values, $6 \mathrm{ppm}$. The high potassium contents seem to be commonly associated with sizable insoluble residues. The 
marbles GMW-2 and F6-B are rich in phlogopite. It was found that the dissolution procedure was vigorous enough to dissolve about one-half this mica. The values reported for samples with potassic noncarbonate fractions will therefore tend to be intermediate between the values of the whole rock and the pure carbonate fraction. The weight per cent of insoluble residues is given in column 3.

The $K / U$ ratio in pure limestones such as the Spergen $\mathrm{fm}$. and the Leadville ls. may be as low as 25 . This ratio is lower than that in average igneous rocks by a factor of 400 , and would yield a value of $R$ of $3 \times 10^{3}$. This difference is due to the great decrease in the potassium content since the uranium values remain roughly the same for these materials.

The marbles show a range in $K$ content similar to that found in limestones. All of the marbles contained some dolomite. Sample GMW-2 contains phlogopite, the larger part being in the +80 sieve fraction. This effect is clearly seen in the results on the total rock and the $-40+80$ sieve fraction. Of the two Franklin marbles, F6-B contains some phlogopite. Sample F6-A was taken in the mine and is from a lithology which contains some coarse biotite crystals. No biotite was observed in the sample analyzed.

Sample fd 7-3 is a white dolomitic marble

TABLE 6. Analytical Data of Potassium and Uranium in Carbonates

\begin{tabular}{|c|c|c|c|c|c|}
\hline Samples & $\begin{array}{c}\% \\
\text { Aragonite }\end{array}$ & $\begin{array}{l}\text { Wgt. \% } \\
\text { Residue }\end{array}$ & ppm K & ppm U & $\mathbf{K} / \mathbf{U}$ \\
\hline \multicolumn{6}{|l|}{ LIMESTONES } \\
\hline Buckhorn & 59 & 10.2 & 321 & & \\
\hline $\begin{array}{l}\text { Buckhorn residue } \\
\text { Cretaceous Chalk }\end{array}$ & 0 & 1.4 & $\begin{array}{r}2220 \\
198\end{array}$ & $1.08^{2}$ & 188 \\
\hline Chicago Formation & Dol. & 0.7 & 131 & $0.01^{2}$ & 13100 \\
\hline Basal Coquina & 46 & 0.6 & 112 & $0.87^{2}$ & 147 \\
\hline Pr 2-Algal Isl. & 0 & & 6 & $1.41^{2}$ & 4.25 \\
\hline Muschel Kalk & 0 & 17.1 & 4600 & & \\
\hline Muschel residue & & & 2900 & & \\
\hline Oolites $(0-03)$ & 98 & 0.1 & 87 & $3.4^{1}$ & 25.6 \\
\hline GMW-2 $(-40+80)$, marble & 0 & 4.1 & 1000 & & \\
\hline $\begin{array}{l}\text { Gimw-2, total nand } \\
\text { spec. crushed marble }\end{array}$ & 0 & 7.1 & 2100 & & \\
\hline fd $7-3$, marble & & 43.2 & $\leq 5$ & $0.083^{4}$ & $<60$ \\
\hline fd $7-2$, marble & & $<0.3$ & 235 & $0.640^{4}$ & 390 \\
\hline F6-A Franklin Marble & $\mathbf{0}$ & $<0.1$ & 40 & $0.12^{2}$ & 333 \\
\hline F6-B Franklin Marble & 0 & 1.6 & 384 & & \\
\hline Leadville Limestone 32 & 0 & 0.4 & 58 & $0.28^{2}$ & 207 \\
\hline Leadville Limestone 82 & 0 & 0.4 & 6 & $0.24^{2}$ & 25 \\
\hline Leadville Limestone 128 & 0 & 0.3 & 20 & & \\
\hline Spergen Formation & 0 & 0.4 & 25 & $1.02^{2}$ & 24.5 \\
\hline Calcite I & 0 & $<0.1$ & $\leq 5$ & $<0.01^{2}$ & \\
\hline Calcite II & 0 & $<0.1$ & $\leq 5$ & & \\
\hline Calcite III & 0 & $<0.1$ & $\boldsymbol{\theta}$ & & \\
\hline \multicolumn{6}{|l|}{ MODERN SHTLLSS } \\
\hline 1336 & 99 & $<0.1$ & 102 & & \\
\hline 1337 & 100 & & 74 & & \\
\hline 1338 & 100 & & 38 & & \\
\hline 1339 & 100 & & 54 & & \\
\hline 1345 & 99 & $<0.1$ & 79 & & \\
\hline 1348 & 100 & $<0.1$ & 35 & & \\
\hline S-07 (B) & 100 & & 153 & $0.013^{1}$ & $11.77 \times 10^{2}$ \\
\hline S-11 & 100 & 0.3 & 62 & $0.012^{1}$ & $5.17 \times 10^{\circ}$ \\
\hline S-13 & 99 & 0.4 & 51 & $0.067^{1}$ & $0.76 \times 10$ \\
\hline S-14 & 100 & & 39 & $0.022^{1}$ & $1.77 \times 10^{2}$ \\
\hline S-15 & & & 44 & $0.032^{1}$ & $1.38 \times 10^{2}$ \\
\hline S-17 & & 0.6 & 154 & $0.041^{1}$ & $3.76 \times 10^{2}$ \\
\hline
\end{tabular}


containing 65 per cent dolomite and 35 per cent diopside. The residue of this sample was found to contain $61 \mathrm{ppm}$ of potassium. Sample fd 7-2 is a dolomitic marble containing 0.26 per cent graphite. These samples were given to us by Dr. B. Doe, who determined the uranium contents in the course of another investigation.

Samples of calcite spar were run for comparison. It is evident that these carbonates have extremely low levels of potassium as suggested by A. E. Engel (personal communication).

In order to determine whether any potassium is present in the original shell materials which constitute limestones as distinct from contributions from clay materials and detrital particles, analyses were made of modern and fossil shells and corals. The concentration of potassium in both modern shells and corals are roughly the same and range from 30 to $150 \mathrm{ppm}$. It follows that these materials contain a significant amount of this element when formed. Many of the purer limestones have $K$ concentrations lying inside of this range. Some inorganically precipitated $\mathrm{CaCO}_{3}$, such as the calcite spar, has virtually no potassium; however, the oolite sample gave a result comparable with the shells and corals. These data suggest that carbonates precipitated from sea water will have some potassium in chemical combination. On the other hand, it is possible that some potassic clays may be contained in all these precipitates.

Some well preserved fossil shells were analyzed for K. Samples I and II were large complete specimens which were carefully cleaned to eliminate any contamination. Sample III was taken from a glauconite-rich matrix and a small amount of contamination with this mineral could easily cause this high result, while it appears that under optimal circumstances the potassium content of shells may be preserved in fossils. The concentration levels are very low but it may be possible to utilize these materials for $\mathrm{A}^{40}-\mathrm{K}^{40}$ dating with the most modern techniques. Assuming complete retention for sample I, this would correspond to $2 \times 10^{-8} \mathrm{cc} \mathrm{STP} / \mathrm{g}$ of $A^{40}$. While this is readily measurable, the

TABLE 6. Continued

\begin{tabular}{|c|c|c|c|c|c|}
\hline Samples & $\begin{array}{c}\% \\
\text { Aragonite }\end{array}$ & $\begin{array}{l}\text { Wgt. \% } \\
\text { Residue }\end{array}$ & ppm K & ppm U & $\mathrm{K} / \mathrm{U}$ \\
\hline \multicolumn{6}{|l|}{ FOSSIL SHELLS } \\
\hline I & 99 & 0.2 & 29 & & \\
\hline II & 100 & 0.3 & 27 & & \\
\hline III Shell Fragments & 99 & 0.7 & 201 & & \\
\hline \multicolumn{6}{|l|}{ MODERN CORAL } \\
\hline Coral I (0-04) & 70 & & 31 & $2.5^{1}$ & 12.4 \\
\hline Coral II (0-05) & 99 & 0.3 & 50 & $3.2^{1}$ & 15.6 \\
\hline \multicolumn{6}{|l|}{ Bikini Corals: } \\
\hline $\begin{array}{ll}\text { Tare, depth } & 4^{\prime} \\
& 13^{\prime}\end{array}$ & $\begin{array}{l}51 \\
49\end{array}$ & $\begin{array}{l}0.2 \\
0.3\end{array}$ & $\begin{array}{l}35 \\
43\end{array}$ & $\begin{array}{l}2.3-3.2^{3} \\
4.2-5.2 \\
2.2-3.2\end{array}$ & $\begin{array}{l}12.5 \\
11.6\end{array}$ \\
\hline $\begin{array}{l}34^{\prime} \\
63^{\prime}\end{array}$ & $\begin{array}{l}89 \\
73\end{array}$ & $\begin{array}{l}0.1 \\
0.2\end{array}$ & $\begin{array}{l}60 \\
65\end{array}$ & $6.5-8.1$ & 8.2 \\
\hline $90-1 / 2^{\prime}$ & 66 & 0.1 & 85 & $4.7-5.7$ & 15.7 \\
\hline $97^{\prime}$ & 51 & 0.6 & 63 & $\begin{array}{l}3.1-4.0 \\
4.1-4.9\end{array}$ & 12.4 \\
\hline Roger, depth $4^{\prime}$ & 66 & 0.5 & 46 & $3.3-4.1^{3}$ & 12.4 \\
\hline $\mathbf{8}^{\prime}$ & 62 & 0.5 & 67 & $4.3-5.1$ & 14.3 \\
\hline $23^{\prime}$ & 62 & 0.3 & 96 & $3.4-4.2$ & 25.0 \\
\hline $44^{\prime}$ & 97 & 0.2 & 43 & $6.1-7.5$ & 6.3 \\
\hline \multicolumn{6}{|l|}{ FOSSIL CORAL } \\
\hline 1437 Reef Coral & 99 & & 63 & & \\
\hline
\end{tabular}

1 M. Tatsumoto and E. D. Goldberg (Colorimetric) Geochim. et Cosmochim. Acta, 17, 201, 1959.

2 B. O. Goldberg (Fluorescence) personal communication.

a M. Coops (Neutron activation) personal communication.

- B. Doe (Isotope dilution) Thesis, Calif. Inst. of Technology, 1960. 
problem of correction for atmospheric argon would be formidable.

The shells appear to have a uranium concentration about 100 times smaller than the corals. The $\mathrm{K} / \mathrm{U}$ ratios for the shells are much closer to the values for average igneous rocks than the corals which have ratios 1000 times smaller.

The ashed bones of 15 different modern vertebrates were also analyzed to investigate the possibility of dating appropriate fossil materials. The total range in concentration was found to be from 400 to $3000 \mathrm{ppm}$. This is a much higher level than found in shells. If it is assumed that this potassium is in the apatite crystals rather than in fluids in the marrow, it may be possible to date well-preserved fossil bone of Cretaceous age.

Acknowledgments. We would like to thank Dr. H. A. Lowenstam for providing us with many of the samples of limestones and shells. The authors are indebted to Mr. Theodore Wen and Mrs. Dorothy Settle for their careful work on the potassium determinations.

\section{TABLE 7. Descriptive Data}

LIMESTONES

Buclchorn, Mid-Pennsylvanian, Sulphur, Okla.

Cretaceous Chalk, Campanian, Vigny, France

Chicago Formation, Niagaran, reef core, Thornton, Ill.

Basal Coquina, Devonshire Marine Isl., Grape Bay, Bermuda

$\operatorname{Pr}$ Q, Mid-Eocene, Algal Isl., Puerto Rico

Muschel Kalk, Mid-Triassic, Rorigliana, Italy

Oolites (0-03) Bahama Bank about 1 mile S.E. of S. Pt. Cat Cay $79^{\circ} 15^{\prime} \mathrm{W}, 25^{\circ} 30.5^{\prime} \mathrm{N}$ water depth 3 feet (recent)

GMW-2 (-40+80 Mesh Fraction) Marble, Balducci Quarry, Gouverneur, N. Y.

$G M W-2$, Marble, total hand spec., Balducci Quarry, Gouverneur, N. Y.

Fd7-9 Marble, fetid limestone, shore of Sylvia Lake, N. Y.

Fd7-2 Marble, graphitic, 900 level, shaft of No. 3 mine, Balmat, N. Y.

F-6A Marble, New Jersey Zinc Mine, Franklin, N. J.

$F-6-B$, Franklin Marble, Franklin, N. J.

$\left.\begin{array}{l}\text { LV-32, Elk Creek Colo., zone } 1 \\ L V-82, \text { Barites Cabin, Colo., zone } 2\end{array}\right\}$

$L V-128$, Sweet Water Lake, Colo., zone 1]

Leadville Limestone

These samples are described by Engel and Engle. Ms. in preparation Spergen Formation, Oolitic portion of the Spergen Formation, Mississippian, St. Genevieve, Missouri Calcile I, Iceland Spar

Calcite II, Manhatten, Nev.

Calcite III, Spar 611, Hockerville, Okla.

\section{SHells}

1396 Lodakia Orbicularis, Belmont Isl., Queens Free Cave, Ferry Rd., Bermuda

1337 Laevicardium Leevigatum (recent) ( $\mathrm{TM}_{2}$ ), Patorreef Lagoon, Bermuda

1388 Lodakia Orbicularis (recent), Whalebone Bay, Bermuda

1389 Laevicardium Laevigatum (Pleist.), Basal Devonshire, Marshall Isl., Bermuda

1945 Conus Californianus (recent), Naval Base E. Santa Barbara, Calif.

1348 Conus Californianus (Pleist.), Hilltop Quarry, San Pedro, Calif.

$S-07$ (B) Haliotis Corrugata, La Jolla, Calif.

S-11 Littorine Planaxis, La Jolla, Calif.

S-13 Acmeca Limatula, La Jolla, Calif.

S-14 Olivella Biplicata, La Jolla, Calif.

S-15 Acantbina Spirata, La Jolla, Calif.

S-17 Tetraclita squamose, La Jolla, Calif.

Fossil Shelis

Fossil I Crassatelites Vadosus, L. Maestrichtian, Ripky Formation, Coon Creek, Tenn.

Fossil II Trigonia Stantoni, Coon Creek, Tenn.

III Shell Fragments Mathews Landing Marl., Paleocene, Wilcox Co., Ala.

\section{Coral}

Coral I (0-04) Key Largo Is. (Diploria labysinthiformis)

Coral II (0-05) Key Largo Is. (Montastrea Annulasis)

Bikini Coral taken at different depthe

1497 Reef Coral Pleistocene, Bermuda

(Manuscript received April 12, 1960; revised October 11, 1960.) 